\title{
Illiquidity or Credit Deterioration: A Study of Liquidity in the US Corporate Bond Market during Financial Crises
}

\author{
Nils Friewald* Rainer Jankowitsch†, Marti Subrahmanyam \\ First Version: April 30, 2009 \\ This Version: July 1, 2009
}

\begin{abstract}
We use a unique data-set to study liquidity effects in the US corporate bond market, covering more than 30,000 bonds. Our analysis explores time-series and cross-sectional aspects of corporate bond yield spreads, with the main focus being on the quantification of the impact of liquidity factors, while controlling for credit risk. Our time period starts in October 2004 when detailed transaction data from the Trade Reporting and Compliance Engine (TRACE) became available. In particular, we examine three different regimes during our sample period, the GM/Ford crisis in 2005 when a segment of the corporate bond market was affected, the sub-prime crisis since mid-2007, which was much more pervasive across the corporate bond market, and the period in between, when market conditions were more normal.

We employ a wide range of liquidity measures and find in our time-series analysis that liquidity effects explain approximately one third of market-wide corporate yield spread changes, in general, and are even more pronounced during periods of crisis. In particular, the price dispersion measure proposed by Jankowitsch, Nashikkar and Subrahmanyam (2008) explains about half of the aggregate bond yield spread changes during the sub-prime crisis. Our dataset allows us to examine in greater detail liquidity effects in various segments of the market: financial sector firms which have been particularly affected by the crisis vs. industrial firms, investment grade vs. speculative grade bonds, and retail vs. institutional trades. In addition, our cross-sectional analysis shows that liquidity explains a large part of the variation in yield spreads across bonds, after accounting for credit risk. These results yield important insights regarding the liquidity drivers of corporate yield spreads, particularly during periods of crisis.
\end{abstract}

JEL-Classification: G01, G12, G14.

Keywords: liquidity, corporate bonds, financial crises, price dispersion, OTC markets.

*Vienna University of Economics and Business, Department of Finance and Accounting, Heiligenstädter Straße 46-48, 1190 Vienna, Austria; email: nils.friewald@wu.ac.at

$\dagger$ Vienna University of Economics and Business, Department of Finance and Accounting, Heiligenstädter Straße 46-48, 1190 Vienna, Austria; email: rainer.jankowitsch@wu.ac.at

$\ddagger$ New York University, Stern School of Business, Department of Finance, 44 West Fourth, Room 9-68, New York, NY 10012; email: msubrahm@stern.nyu.edu 


\section{Introduction}

The on-going global financial crisis had its origins in the US sub-prime mortgage market in 20062007 , but has since spread to virtually every financial market around the world. The most important aspect of this crisis that sharply distinguishes it from previous crises is the rapidity and degree to which both liquidity and credit quality of several asset classes have deteriorated. While clearly both liquidity and credit risk are key determinants of asset prices, in general, it is important to quantify their relative effects and, particularly, how much they changed during the crisis. It is also relevant to ask if there are interactions between these factors, and whether these relationships changed substantially in magnitude and quality from prior periods. In this paper, we study liquidity effects in the US corporate bond market for the period October 2004 to April 2008 including the GM/Ford downgrades and the on-going sub-prime crisis, using a unique data-set covering basically the whole US corporate bond market. We employ a wide range of liquidity measures to quantify the liquidity effects in corporate bond yield spreads. Our analysis explores the time-series and cross-sectional aspects of liquidity for the whole market as well as various important segments.

Most major financial markets, including those for equity, foreign exchange, credit and commodities, have been severely affected in terms of price and liquidity in the current sub-prime crisis. However, the impact has been disproportionately felt in the fixed income markets, including the markets for collateralized debt obligations (CDO), credit default swaps (CDS) and corporate bonds. An important point to note is that these securities are usually traded in over-the-counter (OTC) markets, where there is no central market place, or even a clearing house. Indeed, this aspect has come under regulatory scrutiny since the near-collapse of the CDS market, which was an opaque OTC market. It is the OTC structure of fixed income markets that makes research, especially on liquidity effects, difficult as traded prices and volumes are not readily available, and important aspects can only be analyzed based on quotations from individual dealers, which may not necessarily be representative of the market as a whole.

US corporate bonds trade in an important OTC market. This market is an ideal laboratory to examine liquidity and credit factors because of the following important reasons: First, in contrast to most other OTC markets, detailed data are available on prices, volumes and other market variables since 2004, through an effort of the Financial Industry Regulatory Agency (FINRA), known as the Trade Reporting and Compliance Engine (TRACE). This database aggregates virtually all transactions in the US corporate bond market, which is unusual for any OTC market. Second, the US corporate bond market bore the brunt of the sub-prime crisis in terms of credit deterioration, almost to the same extent as the credit derivatives market to which it is linked by arbitrage/hedging activities. Third, there is considerable variation in credit quality as well as liquidity in this market, both over time and across bonds, providing researchers with the opportunity to examine the differences arising out of changes in liquidity, at the market as well as individual bond level.

For our empirical analysis, we combine all traded prices from TRACE with market valuations from Markit, bid-ask quotations and bond characteristics from Bloomberg, and credit ratings from Standard \& Poor's. This combined data-set is perhaps the most comprehensive one of the 
US corporate bond market assembled to date, covering 31,911 bonds and 4,482 firms. This data-set enables us to study liquidity effects for virtually the whole bond market, including bond segments that show very low trading activity. ${ }^{1}$

The main focus of our research in this paper is to determine the quantitative impact of liquidity factors, while controlling for credit risk and other bond characteristics. To do so, we focus on the yield spread of a corporate bond, defined as its yield differential relative to that of a risk-free benchmark of similar duration. The benchmark could be either the Treasury bond or the swap rate curve.

In order to measure liquidity both at the level of individual bonds and the aggregate market, we consider several alternative proxies. First, we employ bond characteristics that have been used as liquidity proxies in many studies. Second, we use directly observable trading activity variables at the individual bond level (e.g., the number of trades), and the market-wide level (e.g., the number of traded bonds). Third and most important, we employ several alternative liquidity measures proposed in the literature, i.e., the Amihud, Roll, zero-return, no-trade, bid-ask spread and price dispersion measure. The price dispersion measure introduced in Jankowitsch et al. (2008) is particulary important, as it turns out that it captures a significant part of the liquidity effects. This measure is based on the dispersion of traded prices around the consensus valuation by market participants, thus providing an estimate of effective transaction costs.

In the first part of our analysis, we examine the time-series behavior of the bond yield spread changes of the aggregate market and quantify the credit and liquidity component. The credit factor in these regressions is based on the credit rating of the bond, while several proxies are considered for the liquidity factor. In the first set of regressions, we try to distinguish between credit and liquidity effects for the whole time-series, as well as for three different regimes during our sample period, i.e., the GM/Ford crisis, the sub-prime crisis and the period in between, when market conditions were more normal. We compare the results for the individual liquidity proxies and assess their quantitative impact on bond yield spreads.

Overall, we find that the specified regression models explain about one-half of the time-series variation of the yield spread changes. The credit rating, the price dispersion and the Roll measure exhibit statistically as well as economically significant results. The price dispersion measure has the greatest explanatory power for changes in aggregate bond yield spreads in our time-series analysis. Surprisingly, neither direct measures of trading activity, such as trading volume, nor other liquidity measures, show significant explanatory power. Furthermore, we find that the effect of the liquidity measures is far stronger in both the GM/Ford crisis and the sub-prime crisis: the coefficient of the price dispersion measure nearly doubles in these regimes. In the normal period in between, we find no explanatory power for the liquidity measures, indicating that at the market-wide level the liquidity impact or its risk premium stays at the same low level for this period.

We then compare the liquidity for different segments of the bond market. First, the liquidity effects are likely to be different for financial versus industrial (i.e., non-financial) firms. Second, the liquidity impact is expected to be stronger for speculative grade bonds compared with investment

\footnotetext{
${ }^{1}$ This is a major difference between our research and other related recent papers on the financial crises that, in general, focus on the most liquid bonds (see Bao et al. (2009) and Dick-Nielsen et al. (2009), for example.)
} 
grade bonds, if liquidity concerns cause investors to abandon the junk bond market in favor of investment grade bonds in a flight-to-quality. Third, we examine the liquidity effects for different investor groups. We do so by a detailed examination of retail (small) vs. institutional (large) trades to see if there were any differences in the liquidity impact in these two segments of the market.

We find that the overall liquidity of bonds issued by financial firms is higher on average, than those of industrial firms. However, bonds of financial firms also react more strongly to changes in liquidity than their industrial counterparts. Overall, we find evidence that during the subprime crisis, the yield spread increase for financial firms compared to industrial firms is driven relatively more by credit risk. Comparing investment grade to speculative grade bonds, we find lower liquidity for speculative grade bonds as well as a stronger reaction to changes in liquidity. In general, these results show that the liquidity component is far more important in explaining the yield spread for speculative bonds. Analyzing retail trades vs. institutional trades, we find that retail investors are confronted with far higher transaction costs, i.e., they perceive the corporate bond market to be relatively less liquid. However, institutional investors seem to react more strongly to liquidity changes than their retail counterparts.

In the second part of our empirical analysis, we examine the cross-sectional behavior of the yield spread. As in the case of the aggregate market, the liquidity effect for individual bonds is measured for alternative liquidity proxies to examine their relative performance. In general, the cross-sectional results paint a picture similar to the time-series analysis, i.e., liquidity is an important driver of cross-sectional differences in yield spreads, with the price dispersion measure showing the sharpest effects. Interestingly, in the cross-section, trade volume as a direct measure of trading activity and bond characteristics also show significant effects on the yield spreads. The results further indicate that even in the normal period, part of the cross-sectional differences of yield spreads is driven by liquidity, although liquidity had no significant effect in the time-series for this period. The cross-sectional differences due to liquidity are, as expected, stronger in times of crisis, confirming the time-series results.

We present a survey of the relevant literature in Section 2 of the paper, focusing mainly on papers relating to liquidity effects in corporate bond markets, rather than liquidity effects in financial markets, in general. In Section 3, we explain, in detail, the composition of our data-set and the filters and matching procedures we employ in combining data from four different data sources. Section 4 discusses the alternative measures of liquidity that have been proposed and used in the literature and their pros and cons. We focus, in particular, on the relevance of these measures for a relatively illiquid, OTC market. In Section 5, we outline the methodology, together with the basic hypotheses being tested in the paper and the economic motivation behind them. Section 6 presents the time-series results and the results for the cross-sectional analysis. Section 7 concludes.

\section{Literature Survey}

The academic literature on liquidity effects on asset prices is vast. Much of this literature focuses on the impact of liquidity and liquidity risk on equity returns. An early paper was by Amihud and 
Mendelson (1986), who first made the conceptual argument that transaction costs result in liquidity premia in asset prices in equilibrium. In turn, this causes the expected returns for investors with different trading horizons to deviate to compensate for the differences in their transaction costs. Following from this argument, there is an implicit clientele effect in equilibrium, under which illiquid securities are cheaper and yield higher expected returns to compensate for their illiquidity, and are held by investors with longer horizons, while liquid securities have the opposite characteristics. In the cross-section of assets, we would, therefore, observe a relationship between illiquidity and expected returns on an asset, holding other factors constant. This conclusion has been extended and modified in different directions and also tested in a host of asset markets. This literature, focusing mainly on equity markets, is surveyed by Amihud et al. (2006).

Recent papers on credit risk modeling provide evidence for this theoretical argument for the corporate bond market and show that risk-free interest rates and credit risk are not the only factors that drive corporate bond prices. This result has been established based on reduced-form models (see, for example Longstaff et al. (2005)), and structural models (see, for example Huang and Huang (2003)), i.e., neither credit risk measured by the prices of CDS contracts nor asset value information from the equity market, can fully explain corporate bond yields. These papers argue that liquidity is likely to be an important additional factor to consider. They provide some support for this conclusion, however, based on market-wide rather than on detailed bond-specific evidence.

The empirical literature on liquidity effects in corporate bonds is much smaller than that for equity markets, and mostly based on recent evidence. An early exception is the paper by Fisher (1959), who used the amount outstanding of a bond as a measure of its liquidity to show that the yield spreads on (illiquid) bonds with a low amount issued tend to be higher. Recent papers suggest a whole range of liquidity proxies in the context of corporate bond markets. Several authors study the impact of liquidity, based on corporate yields or yield spreads over a risk-free benchmark. Most of these papers rely on indirect proxies based on bond characteristics such as the coupon, age, amount issued, industry, and credit rating; some papers additionally use market-related proxies based on trading activity such trade volume, number of trades, number of dealers and the bidask spread, see e.g., Elton et al. (2001), Collin-Dufresne et al. (2001), Houweling et al. (2005), Perraudin and Taylor (2003), Eom et al. (2004), Liu et al. (2004), Longstaff et al. (2005), and De Jong and Driessen (2006), Edwards et al. (2007). Basically, all these papers find that liquidity is priced in bond yields. However, they find different magnitudes and varying importance of these basic liquidity proxies, but mostly at the market-wide level.

In the more recent literature, several alternative liquidity measures that are estimators of transaction costs, market impact or turnover, have been proposed and applied to analyze liquidity in the corporate bond market at the level of individual bonds. The Roll measure (see Roll (1984) and Bao et al. (2009)) interprets the subsequent prices as arising from the 'bid-ask bounce': thus, the autocorrelation in price changes provides a simple liquidity measure. A similar idea to measure transaction costs is proposed and implemented in the LOT measure proposed by Lesmond et al. (1999). The Amihud measure (see Amihud (2002)) relates the price impact of a trade to the trade volume. Trading activity itself is used in the zero-return measure based on the number 
of unchanged sequential prices and the no-trade measure based on time periods without trading activity (see e.g., Chen et al. (2007)). Mahanti et al. (2008) propose another measure known as latent liquidity that is based on the institutional holdings of corporate bonds, which can be used even in the absence of transaction data, and show that this relationship is robust and correlates well with other measure of liquidity. Jankowitsch et al. (2008) develop the price dispersion measure, which is based on the dispersion of market transaction prices of an asset around its consensus valuation by market participants. This metric directly results from a microstructure model of an OTC market, in which market frictions such as search costs for investors and inventory costs for dealers result in dispersion of prices around the fundamental price of the asset. Thus, this measure provides an estimate of effective transaction costs and could potentially be a superior estimate of real transaction costs in OTC markets.

Most of the early papers on bond market liquidity are based only on quotation data as reasonably complete transaction data were not available until a few years ago. However, some papers use restricted samples of the transaction data for certain parts of the corporate bond market to analyze liquidity, including Chakravarty and Sarkar (1999), Hong and Warga (2000), Schultz (2001) and Hotchkiss and Ronen (2002). Many more researchers focused on the issue of liquidity in the corporate bond market since the TRACE data on US corporate bond transactions started to become available in 2002, with more complete transaction data for the whole market being generated since October 2004. This new source of bond price information allows to analyze many different aspects of the US corporate bond market, see e.g., Edwards et al. (2007), Goldstein and Hotchkiss (2007), Mahanti et al. (2008), Jankowitsch et al. (2008), Nashikkar et al. (2009), and Ronen and Zhou (2009).

It would be especially interesting to examine how liquidity affects the corporate bond market in times of financial crisis. This is the central research question of the current paper. While much of the research on the current financial crisis is probably in progress, two recent papers do provide some early evidence on the impact of liquidity in the US corporate bond market, with some analysis of the early part of the crisis period. These include Bao et al. (2009) and Dick-Nielsen et al. (2009). Since these papers are more directly related to our own research, we present a brief summary of these papers and discuss the additional insights our paper provides.

Bao et al. (2009) use the TRACE data to construct the Roll measure as a proxy for liquidity. They use only bonds that existed prior to October 2004 from Phase I and II of the TRACE project, when the bond coverage was incomplete (around 1,000 bonds), and cover the period April 2004 to December 2008. They show that illiquidity measured by the Roll measure is quite significant in this market and much larger than would be predicted by the bid-ask bounce. At the market-wide level, their measure correlates with measures of market sentiment such as the CBOE VIX measure of equity market volatility. They also show that their measure exhibits commonality across bonds, which tends to go up during periods of market crisis. Further, they show that their measure is smaller for higher trade sizes. Finally, they relate the Roll measure to bond yield spreads in a cross-sectional regression setup and provide evidence that part of the yield spread differences across bonds is due to illiquidity.

Dick-Nielsen et al. (2009) combine the TRACE data using straight bullet bonds (around 4,000 
bonds), with accounting data and equity volatility, as proxies for credit risk, for the time period October 2004 to March 2008. They use a panel regression based on quarterly data to study the effects of five different liquidity measures and the defined credit risk variables. In general, they find a significant effect of liquidity, which increased with the onset of the sub-prime crisis. The price impact of trades and transaction costs are the most important measures in their sample. However, their multivariate regression results show somewhat mixed results for different rating classes.

There are several important differences between these prior papers and our own research in this paper. First, we employ a much larger data-set on transaction data on US corporate bonds than any prior papers, as we basically cover the whole traded market consisting of 31,911 bonds. This is a major difference even compared with the recent work of Bao et al. (2009) and Dick-Nielsen et al. (2009), who cover only a certain, generally the more liquid, sub-segment of the market. We think that an important contribution of our paper is to present results for virtually the whole bond market and, especially, for rather illiquid segments. While conclusions regarding the more liquid segments of the market are interesting, it is important to remember that liquidity effects are likely to be exacerbated in the segments with less trading activity, for which most of the prior work has no evidence to offer. Second, based on this data-set we are able to examine liquidity effects in important segments of the market such as bonds of financial versus industrial firms, investment versus speculative grade bonds, and retail versus institutional trades in greater detail. Third, our research explicitly covers two crisis periods, which are analyzed separately: the broader sub-prime crisis, which is on-going, and the earlier, GM/Ford crisis, which affected particular segments of the US corporate bond market. We contrast the behavior of liquidity and its pricing in bond yield spreads, during periods of crisis with more normal periods. Fourth, we include the additional information on the market's consensus valuation of bonds provided by Markit. These data permit us to estimate the price dispersion measure for the bonds in our sample and, thus, include an important additional measure of transaction costs. This is particularly relevant for our research question, as other proxies for transaction costs appear to be less clearly related to liquidity in OTC markets.

\section{Data Description}

In this section we present the unique data-set we have at hand for this liquidity study covering basically the whole US corporate bond market. Our data are drawn from several different sources:

1. Transaction data from the Trade Reporting and Compliance Engine (TRACE),

2. Consensus market valuations from Markit,

3. Bid-ask quotations from Bloomberg,

4. Credit ratings from Standard \& Poor's,

5. Bond characteristics from Bloomberg and

6. Treasury and swap data from Bloomberg. 
Our time period starts with the date when TRACE was fully implemented on October 1, 2004, and covers the period until April 30, 2008. TRACE provides detailed information about all transactions in the US corporate bond market, i.e. the actual trade price, the yield based on this price as well as the trade volume for each transaction. ${ }^{2}$ Phase I of TRACE was launched by the Financial Industry Regulatory Agency (FINRA) in July 2002 with the aim of improving transparency in the US corporate bond market. This phase covered only the larger and generally higher-credit quality issues. Phase II expanded the coverage and dissemination of information to smaller investment grade issues. Since the final Phase III was implemented on October 1, 2004 , transactions of essentially all US corporate bonds have been reported. Hence, the TRACE database has been reasonably complete since its final implementation. This data source is almost unique for an OTC market, since in many other cases, price information usually must be obtained either from an individual dealer's trading book, which provides a very limited view of the market, or by using bid-ask quotations instead. However, in the US corporate bond market reporting of any transaction is obligatory for brokers and dealers and follows a set of rules approved by the Securities and Exchange Commission (SEC), where all transactions must be reported within a time frame of 15 minutes.

We use certain filters for the TRACE data to eliminate potentially erroneous data points: First, we delete reported trades that are obviously incorrect and subsequently corrected or deleted. ${ }^{3}$ Second, we follow Edwards et al. (2007) and apply a median filter and a reversal filter to eliminate further potential data errors. Whereas the median filter identifies potential outliers in reported prices within a certain time period, the reversal filter identifies unusual price movements. ${ }^{4}$ Eliminating any potential errors in the reported transactions reduces the number of reported trades by roughly $5 \%$ to 20.7 million trades. We finally end up with a data sample consisting of 31,911 bonds from 4,482 issuers. Most bonds are not traded on a daily basis: on average, per day, we observe about 6,900 traded bonds, 21,000 trades, and $\$ 8.7$ billion in volume.

We merge the (filtered) TRACE database with an important additional source for the market's valuation of a bond, which we obtained from Markit Group Limited, a leading data provider, specialized in security and derivatives pricing. One of its services is to gather, validate and distribute end-of-day composite bond prices from dealer polls. Up to thirty contributors provide data from their books of record and from feeds to automated trading systems (see Markit (2006)). These reported valuations are averaged for each bond after eliminating outliers. Hence, this price information can be considered as a market-wide average or expectation of a particular bond price, reflecting the market consensus. The Markit valuations are used by many financial institutions to mark their portfolios to market and have credibility among practitioners. In total, we have 4,635,765 Markit quotes, covering 26,597 bonds in our database.

The third data-set we merge into our database consists of end-of-day bid/ask quotations reported by Bloomberg. Bid-ask spreads are widely used as a liquidity proxy in academic studies

\footnotetext{
${ }^{2}$ The reported trade volume is capped at $\$ 1$ million for high yield and unrated bonds and at $\$ 5$ million for investment grade bonds.

${ }^{3}$ To be more precise, we eliminated any transaction that needed more than 20 days to settle, had a negative reported price, were reported multiple times (corrected or deleted transactions) or were simply test cases.

${ }^{4}$ The median filter eliminates any transaction where the price deviates by more than $10 \%$ from the daily median or from a nine-trading-day median centered at the trading day. The reversal filter eliminates any transaction with an absolute price change deviating from the lead, lag and average lead/lag price change by at least $10 \%$.
} 
and they are an important, albeit noisy, price metric for OTC markets where trades are not reported to a central authority. Thus, in this study we can directly compare the performance of this commonly used measure compared to other liquidity proxies using transaction information. In all, we have 4,647,788 bid-ask quotations for 17,213 bonds at hand.

In order to control for default risk, we use credit ratings from Standard \& Poor's (S\&P). We focus on long-term, issue credit ratings as the market's current judgement of the obligor's creditworthiness with respect to a specific financial obligation. It should be noted, that in our descriptive statistics of the rating variable, we assign integer numbers to ratings, i.e., AAA $=1$, $\mathrm{AA}+=2$, etc. Our time-period contains 23,531 bonds, which have at least one S\&P credit rating each. Note that credit risk could be measured using alternative approaches. Two prominent examples come to mind: using CDS spreads in the context of a reduced-form credit risk model, as in Longstaff et al. (2005), or using accounting based/equity related data in a structural model context, as in Huang and Huang (2003). We do not incorporate such proxies as this information is generally only available for a very small (presumably more liquid) segment of the market and our intention is to explicitly analyze liquidity effects for the whole market. In addition, the impact of the liquidity on these data inputs would also have to be taken into account, rendering the analysis far more complex, and hence, prone to additional error. This is particularly true during periods of crisis when liquidity and counterparty risk considerations are exacerbated in the pricing of CDS as well as equity contracts. Hence, we apply the more parsimonious approach of using only the credit ratings, with their admitted shortcomings, in terms of their own error and failure to anticipate changes in credit risk.

For each bond, we additionally have issue/bond characteristics at hand which we also obtained from Bloomberg. These bond characteristics include the issue date, maturity, age, coupon, amount issued, industry and bond covenants. Most of these characteristics have been considered as simple liquidity proxies by previous studies. Finally, we use swap rates and Treasury rates for various maturities retrieved from Bloomberg as the benchmark for the risk-free interest rate curve to compute the corporate yield spreads. Table 1 provides summary statistics of the yield spreads, ratings, bond characteristics, trading activity variables and liquidity measures. Note that the computational details for the liquidity proxies and the yield spread are presented in the following sections.

\section{Liquidity Proxies}

This section presents the liquidity proxies that we use in the time-series and cross-sectional regressions as explanatory variables. A number of liquidity proxies have been proposed in the literature (see Section 2) which are not all equally effective, given the challenges of obtaining detailed and sufficiently frequent data in the relatively illiquid corporate bond market. Our data-set allows us to compare the proposed proxies in this empirical study. We classify the available proxies into three groups: bond characteristics, trading activity variables and liquidity measures.

Bond characteristics, such as the amount issued, are simple liquidity proxies which provide a

rough indication about the potential liquidity. Trading activity variables, such as the number of trades, provide bond or market-specific information based on transaction data. Liquidity measures 
are alternative estimators of transaction costs, market impact or turnover.

All these liquidity proxies can either be calculated on a daily basis, given that price information is observable on that day or are time-invariant (e.g., coupon.) Most of the proxies can be computed both at the bond and market-wide level. For the cross-sectional regressions, we directly use the time-invariant proxies for each bond and construct bond-level measures of the time-varying liquidity proxies by averaging the daily observations for defined periods. For the time-series regressions, we construct a daily series of market-wide measures by averaging or summing the bond-specific liquidity proxies over all bonds for each day, and calculate additional proxies which are only available at the level of the market (e.g., number of traded bonds.)

In the following sections, we present the definition of the various liquidity proxies that we use in our analysis and discuss details of their computation. Table 1 provides cross-sectional descriptive statistics of the various liquidity proxies and Table 2 presents the correlations between them.

\subsection{Bond Characteristics}

The bond characteristics we consider as liquidity proxies are the amount issued, coupon, maturity, age, and a variable identifying bonds issued by financial firms. These proxies, while admittedly crude measures, make intuitive sense. In general, we expect bonds with a larger amount issued to be more liquid and bonds with larger coupon to be less liquid. Bonds with long maturities (over ten years) are generally considered to be less liquid since they are often bought by buy-and-hold investors, who trade infrequently. Similarly, we expect recently issued (on-the-run) bonds to be more liquid. The industry variable provides information about the different liquidity effects of financial compared to industrial firms. We use these bond characteristics directly in our crosssectional analysis and consider market-wide averages of these proxies in our time-series analysis. However, we expect these variables to be more important in the cross-section than in the timeseries, since averages taken over all bonds traded on a particular day (e.g., the average coupon or the average maturity) do not show much time-series variation. We will discuss this issue in greater detail in the context of our empirical results.

\subsection{Trading Activity Variables}

A market's trading activity, in general, or a bond's trading activity, in particular, provides information about liquidity. In this sense, higher trading activity generally indicates higher liquidity. We consider the following trading activity variables: number of trades, trade volume and number of traded bonds.

We compute the number of trades and the trade volume of a particular bond on each day from the trading information given by TRACE. The market-wide measures are given by the total number of trades and the total trade volume on a particular day for all traded bonds. The number

of traded bonds is a trading activity variable, which is only available at the market-level and is simply the number of bonds traded on a particular day. 


\subsection{Liquidity Measures}

\subsubsection{Amihud Measure}

A well-known liquidity measure originally adopted for the equity market is the Amihud measure by Amihud (2002) that is conceptually based on Kyle (1985). It relates the price impact of trades, i.e., the price change measured as a return, to the trade volume. The Amihud measure at time $t$ for a certain bond over a particular time period with $N_{t}$ observed returns is defined as the average ratio between the absolute value of these returns $r_{j}$ and its trading volumes $v_{j}$, i.e.,

$$
\text { Amihud }_{\mathrm{t}}=\frac{1}{N_{t}} \sum_{j=1}^{N_{t}} \frac{\left|r_{j}\right|}{v_{j}} .
$$

A larger Amihud measure implies that trading a bond causes its price to move more in response to a given volume of trading, in turn reflecting lower liquidity. We use the daily volume-weighted average TRACE prices to generate the returns $r_{j}$ and calculate the Amihud measure on a dayby-day basis. Most other researchers who study liquidity in the corporate bond markets based on transaction data use intra-day (i.e., trade-by-trade) returns which we do not recommend. We argue that in the context of bond markets, due to their OTC nature, consecutive reported trades do not have the same meaning as they do in exchange-traded markets, such as the equity markets, for three reasons: First of all, trades must be reported within 15 minutes, which does not guarantee that reported trades were actually executed in the reported order. However, since the Amihud measure is based on returns it is sensitive to the trading sequence. Second, the OTC structure, in general, implies that trades which take place shortly after each other do not necessarily build upon the information of the previous trade, i.e., price changes caused by consecutive unrelated trades cannot simply be attributed to liquidity effects in OTC markets. Third, it is not unusual that bond dealers often immediately pass on recently acquired bonds to other dealers with only a marginal spread. Obviously, the returns of such back-to-back trades do not reveal liquidity related information, but are microstructure noise.

\subsubsection{Zero-Return Measure}

The zero-return measure is based on the number of unchanged sequential prices of a bond in a given period. Bond prices that stay constant over long time periods are likely to be less liquid, as the information may be stale. Obviously, such a measure can only be based on price quotations or valuations, such as Markit or Bloomberg in our case. Constant price information in these data sources reveal illiquidity as unchanged prices could indicate an incomplete coverage of the bond.

Zero-returns can be calculated with Markit quotes or mid-quotes from Bloomberg data. For the bond-level zero-returns, we relate the number of zero-return observations to the total number of trading days for a particular time period. The market-wide zero-return is given by the fraction of the sum of zero-returns for a particular day to the number of bonds that traded on that day.

\subsubsection{No-Trade Measure}

A variable that can easily be computed with transaction data and that potentially reveals illiquidity is the no-trade measure. This measure is based on the number of days without any trading activity 
observed in the TRACE data-set for a given bond. We expect liquidity to be lower for bonds with a large number of no-trade days. The bond-level measure is simply given as the fraction of the number of no-trade days within a particular time period to the length of that specified time-period. We define the market-wide measure as the fraction of all non-traded bonds to all outstanding bonds on a particular day.

\subsubsection{Bid-Ask Spread}

The bid-ask spread is the first of three measures related to the transaction costs of bonds. Higher transaction costs generally indicate lower liquidity. The calculation is straightforward as this liquidity measure is represented by the difference between the ask and the bid quote reported in Bloomberg. This measure is based only on quotations and is used in most liquidity studies for OTC markets where transaction data is not available. Thus, the comparison of this measure with the Roll and price dispersion measure is especially interesting.

\subsubsection{Roll Measure}

The Roll measure developed by Roll (1984) shows that, under certain assumptions, adjacent price movements can be interpreted as a bid-ask bounce which, therefore, allows to estimate the effective bid-ask spread. This bid-ask bounce results in transitory price movements that are serially negatively correlated and the strength of this covariation is a proxy for the roundtrip costs for a particular bond, and hence a measure of liquidity. More precisely, the Roll measure is defined as

$$
\operatorname{Roll}_{\mathrm{t}}=2 \sqrt{-\operatorname{Cov}\left(\Delta p_{t}, \Delta p_{t-1}\right)},
$$

where $\Delta p_{t}$ is the change in prices from $t-1$ to $t$. As argued earlier in the context of the Amihud measure, the validity of this measure for the corporate bond market is debatable, given its OTC nature. Nevertheless, we compute the Roll measure based on the daily volume-weighted bond prices $p_{t}$ from the TRACE data-set where we use a rolling window of 60 days and require at least 8 observations to determine the covariance. ${ }^{5}$ Note that the Roll measure has the disadvantage that a price history with some minimum number of observations has to available for its calculation.

\subsubsection{Price Dispersion Measure}

A new liquidity measure recently introduced for the OTC market is the price dispersion measure of Jankowitsch et al. (2008). This measure is based on the dispersion of traded prices around the market-wide consensus valuation. A low dispersion around the valuation indicates that the bond can be bought close to its fair value and, therefore, represents low trading costs and high liquidity, whereas high dispersion implies high transaction costs and hence low liquidity. This measure is derived from a market microstructure model and shows that price dispersion is the result of market frictions such as inventory risk for dealers and search costs for investors. It presents a direct estimate of trading costs based on transaction data with the advantage that

\footnotetext{
${ }^{5}$ Alternatively, a trade-by-trade approach could have been used. However, the same arguments as for the Amihud measure apply. Furthermore, according to Bao et al. (2009) a covariance based on daily data is somewhat larger but comparable to the trade-by-trade results.
} 
it is not based on the price history such as the Roll measure. As in Jankowitsch et al. (2008) the traded prices are obtained from TRACE and the market valuations from Markit. The price dispersion measure is defined as the root mean squared difference between the traded prices and the respective market-wide valuation weighted by volume, i.e., for each day $t$ and a particular bond, it is given by

$$
\text { Price Dispersion }_{t}=\sqrt{\frac{1}{\sum_{k=1}^{K_{t}} v_{k}} \sum_{k=1}^{K_{t}}\left(p_{k}-m_{t}\right)^{2} v_{k}},
$$

where $p_{k}$ and $v_{k}$ represent the $K_{t}$ observed traded prices and their trade volumes on date $t$ and $m_{t}$ is the market-wide valuation for that day. Note that we use intra-day data for the calculation of the price dispersion measure. Such a computation is feasible for this measure as the calculation does not depend on the consecutive ordering of trades.

\section{Methodology}

This section outlines our general approach to measuring the impact of liquidity and credit risk on pricing in the US corporate bond market. We present here our definitions of the bond yield spread and the measure of credit risk. We also define the sub-periods of interest as well as the market segments that we study in greater detail. We then present the specifications for our time-series and cross-sectional analysis and the specific hypotheses we test.

\subsection{Bond Yield Spread}

The dependent variable in our setup is the corporate bond yield spread, represented by the yield differential relative to that of a risk-free benchmark. We define this benchmark as the yield of a riskfree zero-coupon bond with a maturity equal to the duration of the corporate bond. We compute this duration based on the reported yield in the TRACE database and the corporate bond's cashflow structure. Note that we do not incorporate adjustments for optionalities or covenants included in the bond structure to determine the duration. Overall, yield spreads based on this duration adjustment can be considered as a proxy for the zero-coupon yield spread taken from a more complete pricing model. ${ }^{6}$

We use both the Treasury yield curve and the swap curve as risk-free benchmarks to calculate the bond yield spreads. We find that the general structure of the resulting yield spread is basically identical for both benchmarks. However, as expected, the yield spread based on the swap curve is shifted downwards compared to the spread based on the Treasury curve indicating that the swap curve represents market participants with AA ratings with greater credit risk. Note that neither for our time-series nor cross-sectional regressions would a pure shift in the general level of the yield spread change the results, since such a shift would be absorbed in the constant term. ${ }^{7}$

\footnotetext{
${ }^{6}$ Given the complexity of these models and the limited information available for its calibration, we presume that the resulting zero-coupon yield spread would not improve the economic interpretation of our results, in general. To test this assumption, we have employed regression analysis for a sub-sample of straight coupon, bullet bonds without any option-features. For this sub-sample, we find virtually identical results, confirming our conjecture.

${ }^{7}$ We have conducted all our regression analysis on both spread series; however, as the results are basically identical, we report only the results for the spreads against the Treasury benchmark in the empirical results section.
} 
We calculate the bond yield spread for every price/yield observation in the TRACE data-set. Thus, we may have more than one spread observation for a given bond on a particular day, since there may be multiple trades for the bond on that day. Hence, to get a single value for the yield spread, we calculate the daily bond spread from the individual observations by calculating a volume-weighted average on a certain day, i.e., we implicitly assume that the spread information is reflected more strongly in large trades on that day.

These daily spread observations for each bond are the basic data used in our regressions. For the cross-sectional regressions, we calculate the count-weighted average yield per bond over all trading days in the particular period (i.e., the simple average across days). For the market-wide time-series model, we also use the count-weighted average of the daily yield spreads over all bonds as the explanatory variable. ${ }^{8}$ Figure 1 shows the corporate bond yield spread based on TRACE, indicating the dramatic increase of the spreads especially in the sub-prime crisis.

\subsection{Credit Rating Variable}

To control for credit risk, we use the $\mathrm{S} \& \mathrm{P}$ credit ratings, as discussed in Section 3. Since these ratings are measured on an ordinal scale, we need to transform them to a cardinal scale. We use two alternative approaches for this transformation: first, by simply assigning numeric values to the rating classes $(\mathrm{AAA}=1, \mathrm{AA}+=2, \ldots, \mathrm{C}=21)$, and second, using these numeric values transformed by an exponential function:

$$
\text { Rating Variable }=\alpha+e^{\left(\beta_{1}+\beta_{2} \cdot \text { Rating Number }\right)}
$$

The exponential form has its motivation in the mapping between rating classes and probabilities of default/expected losses. In general, expected losses and yield spreads are linearly related (see, e.g., Duffie and Singleton (1999)), and both are approximately exponentially related to rating classes (see, for example, Standard \& Poor's (2008).) We calibrated the above equation using the daily spread observations of all bonds (resulting parameters: $\alpha=0.6822, \beta_{1}=-1.7251$ and $\beta_{2}=0.2063$ ). Alternatively, we could have used reported probabilities of default or expected losses from Standard \& Poor's. However, as the reported periods and the samples for the probabilities of default do not perfectly overlap with our sample, we assume that the setup we use reflects the non-linear relation between ratings and bond yield spreads more accurately, as we transform the rating into a variable that is eventually linearly related to the yield spreads.

\subsection{Sub-Periods of Interest}

We are interested in how the explanatory power of the independent variables differs in financial crises compared to normal market environments. Therefore, we define the following three subperiods: The GM/Ford crisis (March 2005 to January 2006) when a segment of the corporate bond market was affected, the sub-prime crisis (July 2007 to April 2008), which was much more pervasive across the corporate bond market, and the normal period in between (February 2006

${ }^{8} \mathrm{We}$ also examine the behavior of bond yield spreads, weighted by volume of trading and by the amount outstanding of the individual bonds. These alternative specifications result in virtually the same results, and thus, we only present the count-weighted version. 
to June 2007). We choose the start and end dates of the sub-periods based on exceptional events that are believed to have affected market conditions (see Figure 2.) $)^{9}$

\subsection{Sub-Segments of Interest}

In addition to the market-wide data series, we define sub-segments based on the following criteria to provide further insights into the issue of liquidity. First, we separate the bonds into those issued by financial and industrial (i.e., non-financial) firms. Even casual evidence suggests that financial firms were much more affected by the sub-prime crisis, which ought to be reflected in the relative importance of credit and liquidity factors for these bonds compared to those of other firms. Second, we analyze investment grade bonds (AAA to BBB-) compared to speculative grade bonds $\left(\mathrm{BB}+\right.$ to $\mathrm{C}$. ${ }^{10}$ Third, we compare bonds traded by retail versus institutional investors. We use the average trade size for each bond on each date as the basis for the classification of trades into these two groups. If the average trade size is below $\$ 25,000$, we consider it to be a bond with mainly retail trading on that day, and if the average trade size is above $\$ 500,000$, we classify it as a mainly institutionally traded bond. ${ }^{11}$ In general, for the cross-sectional regressions, the definition of such sub-groups is not necessary as the industry, rating grade, and trade size information can simply be represented as additional explanatory variables.

\subsection{Time-Series Regression}

In the time-series regressions, we first develop a univariate model for the time-series of bond yield spreads for the specified periods. Given the high degree of autocorrelation observed in the univariate model, we use a model in first differences with one autoregressive parameter in all our specifications. The first differences of the explanatory variables are included in the multivariate specifications, as represented in the equation below: ${ }^{12}$

$$
\begin{aligned}
\Delta(\text { Yield Spread })_{t}= & \alpha_{0}+\alpha_{1} \cdot \Delta(\text { Yield Spread })_{t-1}+\alpha_{2} \cdot \Delta(\text { Rating Variable })_{t} \\
& +\boldsymbol{\beta} \cdot \Delta(\text { Bond Characteristics })_{t}+\boldsymbol{\gamma} \cdot \Delta(\text { Trading Activity Variables })_{t} \\
& +\boldsymbol{\lambda} \cdot \Delta(\text { Liquidity Measures })_{t}+\epsilon_{t}
\end{aligned}
$$

\footnotetext{
${ }^{9}$ Alternative definitions of these sub-periods could have been used. Therefore, as a stability test, we varied the start and end dates of the sub-periods by up to one month and find that our results stay basically identical. In the cross-sectional regressions, we use quarterly periods as an additional stability test. However, we find similar results, and hence, report only results for the three sub-periods defined above.

${ }^{10}$ We use this definition instead of the individual ratings because the more granular classification by the individual rating class results in small samples in several rating buckets. However, regressions run for certain individual credit ratings with sufficient sample size show that the important stylized facts are already reflected by the investment/speculative grade grouping.

${ }^{11}$ This is admittedly a somewhat noisy metric of the type of trader. It is possible that institutional traders break up their trades into small lots. However, our size metric is very small for the retail category and so this may not be too much of a concern. As the TRACE database does not have an identifier for the type of trader, the trade size is the best available proxy. We have also estimated our time-series models for the intermediate trade size bonds, i.e., between $\$ 25,000$ to $\$ 75,000$ and $\$ 75,000$ to $\$ 500,000$. The results for the first intermediate segment is basically identical with the retail group and the second group is almost identical with the institutional group. Therefore, only the evidence for the retail and institutional groups, at the two ends of the trade size spectrum, is presented here.

${ }^{12}$ We investigated alternative specifications for the time-series model, including different lags of the autoregressive and moving average parameters, and find that the results are very similar for these specifications.
} 
Regarding data frequency, our basic time-series data are at a daily frequency. We additionally generate weekly and monthly averages of the time-series variables from the daily data and calibrate all our models on these daily, weekly, and monthly data. In general, the results are very similar for these three series. However, it is important to balance the noise in higher frequency data against the available number of observations. It turns out that the weekly time-series is the best series to work with in this respect. Thus, all the time-series regression results presented in the empirical results section below are based on weekly data.

\subsection{Cross-Sectional Regression}

These regressions are at the bond level and therefore allow for somewhat different analysis compared to their time-series counterparts. The regressions are performed with the bond yield spreads in levels rather than changes with the following structure:

$$
\begin{aligned}
\text { Yield Spread }_{i}= & \alpha_{0}+\alpha_{1} \cdot \text { Rating Variable } \\
& +\boldsymbol{\beta} \cdot \text { Bond Characteristics }_{i} \\
& +\boldsymbol{\gamma} \cdot \text { Trading Activity Variables } \\
i & \boldsymbol{\lambda} \cdot \text { Liquidity Measures }_{i}+\epsilon_{i}
\end{aligned}
$$

In order to account for time-series variation in the yield spreads and explanatory variables we conduct the cross-sectional analysis for the three sub-periods, where we assume that the timevariation within the regimes is negligible. ${ }^{13}$ This approach allows us to analyze liquidity effects in times of regular market conditions and financial crises. For each sub-period, we compute the averages of all variables on the bond level, which requires at least one observation in the defined time window.

An important consideration for this analysis is the sample size: If we require that data for all the independent variables should be available for each bond traded in a particular sub-period we have samples of approximately 10,000 bonds at hand. Alternatively, we could exclude certain independent variables to increase the set of available bonds. It turns out that the only liquidity proxy that has a significant restrictive impact on the sample size of bonds is the bid-ask spread. Thus, by excluding the bid-ask spread as an explanatory variable, we obtain a larger sample comprising of roughly 14,000 bonds. A second point we have to consider, is that the variables for each bond can be based on a markedly different number of observations. Hence, we construct a third sample that consists of generally more actively traded bonds. This sample allows us to test whether those bonds provide different cross-sectional results. For this sample, we use solely straight bullet bonds (around 4,000) without any option-features, as these bonds represent the more actively traded segment. Furthermore, this sample is comparable to those used in other liquidity studies (e.g., Bao et al. (2009) and Dick-Nielsen et al. (2009)). We designate the sample excluding the bid-ask spread as the large sample, the one including all variables as the medium sample and the actively traded sample as the small sample.

\footnotetext{
${ }^{13}$ We confirm this assumption by using quarterly periods as a robustness test.
} 


\subsection{Hypotheses}

Based on the methodology presented above, various hypotheses regarding the effect of liquidity in US corporate bond market can be tested. In the following, we give an overview of the hypotheses we analyze in the results section.

The main issue we study is whether liquidity is priced in the US corporate bond market, in general, and whether the effect of liquidity is stronger in times of financial crises. Our hypothesis is that liquidity is an important priced factor, and an even more important one in financial crises. The time-series regressions would reveal whether changes in liquidity measures, over time, can explain yield spread movements; the cross-sectional regressions explore whether the liquidity variables can explain yield spread differences across bonds. Additionally, the three sub-periods can show the relative importance of the different measures during financial crises compared with the period of more normal market conditions.

The second question is whether bonds of financial firms react more strongly to liquidity in periods of financial crises than industrial bonds. Our conjecture is that, in general, financial bonds are more liquid, on average; however, their yield spreads would react more strongly to changes in liquidity, especially in times of crises.

The third research question is whether the credit rating is related to liquidity effects. In this analysis, we will particularly focus on investment grade vs. speculative grade bonds. Our hypothesis is that liquidity is better in the investment grade sector; however, we expect that this difference would be less pronounced during financial crisis, especially during the sub-prime period.

The fourth question compares retail trading to institutional trading. Our hypothesis is that retail traders are confronted with higher transaction costs, and thus, lower liquidity compared with institutional traders. Again, we presume that this difference would be less pronounced in times of crises.

\section{Empirical Results}

\subsection{Time-Series Analysis}

In this section we present the empirical results for the time-series analysis of the market-wide average bond yield spread based on the credit rating, the liquidity proxies introduced in Section 4 and the methodology presented in Section 5. We provide our results for the overall time-series as well as for the three defined sub-periods (GM/Ford crisis, normal period, and sub-prime crisis.) In the second part of the empirical analysis, we investigate the impact of liquidity for various segments of the market: financial vs. industrial bonds, investment grade vs. speculative grade bonds, and retail vs. institutional trades.

To formally test for the statistical significance of the relationship between the first difference of the yield spread and our independent variables for the overall time-series, we first perform a time-series analysis, considering each variable individually. The following variables have significant explanatory power for the yield spread on a univariate basis: the credit rating, the price dispersion measure, the Roll measure, and the number of trades. As expected, bond characteristics, in general, do not have any explanatory power for the average bond yield spread, since these do not 
show much variation over time at the aggregate level.

The results of the multivariate regressions are presented in Table 3. Column 1 presents the results for a model where all trading activity variables and liquidity measures are included. ${ }^{14}$ The parameter values and significance levels for each variable are essentially identical to the univariate results confirming that the first differences of the independent variables appear to be uncorrelated. Column 2 represents the multivariate regression results based on the significant factors after a stepwise model building. This model includes the rating, the price dispersion measure and the Roll measure as explanatory variables. This regression is one of the key results of this paper. Therefore, we discuss in detail the interpretation of the results of this multivariate specification. ${ }^{15}$

Overall, the model has a relatively high $R^{2}$ of $46.3 \%$, considering that the model is specified in first differences. Notably, the price dispersion measure has the highest marginal $R^{2}$ of $34.6 \%$, whereas the Roll measure has only a marginal $R^{2}$ of $2.2 \%$. The credit rating has a marginal $R^{2}$ of only $2.8 \%$, perhaps since the credit rating of the average bond does not vary much over time. These results show that the price dispersion measure is, by far, the most important variable to explain the time-series behavior of the corporate bond yield spread for the overall time-series. Surprisingly, liquidity measures like the Amihud, the zero-return, and the no-trade measure do not provide any significant explanatory power at the aggregate level. This is also true for trading activity variables such as trade volume, number of traded bonds and trades.

Thus, one important result of this paper is that aggregate yield spread changes over time cannot be explained by trading activity, but rather by measures of the observed transaction costs in the market. This information is, in principle, covered by three variables, i.e., the bid-ask spread, the price dispersion and the Roll measure (see Figure 3 for a comparison.) The bid-ask spread is only a rough proxy of transaction costs, as indicated by its low variation over time (even in the period of the sub-prime crisis. $)^{16}$ When comparing the price dispersion measure and the Roll measure, it turns out that the price dispersion measure is a far better proxy of aggregate liquidity, whereas the Roll measure is a rather noisy proxy.

So far, we have analyzed the statistical significance of the variables of the multivariate model. An important question is whether these variables also have an economically significant impact on changes in the market-wide yield spread. To illustrate the effect of the three statistically significant variables, we present the effect of a one standard deviation move in each of the explanatory variables on the yield spread which has a standard deviation of $14.6 \mathrm{bp}$. The price dispersion measure has, by far, the largest economic impact on yield spread changes. A one standard deviation move in the price dispersion measure causes a 8.5 bp change in the yield spread. In contrast, the credit rating has an impact of only $2.3 \mathrm{bp}$ and the Roll measure of $2.2 \mathrm{bp}$, indicating that these variables are also important in economic terms, but less so. Thus, at the aggregate level, the liquidity effect measured by the price dispersion measure appears to have a greater impact on bond yield spread changes than even the credit rating, probably of the credit rating of the average bond does not change much from one week to the next.

\footnotetext{
${ }^{14}$ Results for the bond characteristics are not presented to conserve space.

${ }^{15}$ We also included interaction terms between the credit rating and liquidity proxies in the multivariate model. However, no significant relation could be found for these interaction terms.

${ }^{16}$ Furthermore, there are questions about the interpretation of the bid-ask spread in an OTC market, as argued by Jankowitsch et al. (2008).
} 
To understand the role of liquidity risk in financial crises, we next analyze three different sub-periods of our overall sample. We present the results for two different crisis periods (the GM/Ford crisis and the sub-prime crisis) and compare it with the period in-between, which can be considered as a period with more normal market conditions. The analysis of simple time-series averages of the variables in these three periods allows us to gain some important insights into the causes of the variation (see Table 4.) The average aggregate yield spread in the normal period of $1.8 \%$ is smaller than in the GM/Ford crisis of $2.2 \%$, and even more so, in the sub-prime crisis of $3.3 \%$, documenting the strong impact of the on-going crisis on yield spreads for the whole market, which is also indicated by Figure 1. The averages of the trading activity variables (number of bonds, number of trades, and volume) are quite illustrative. During the GM/Ford crisis, trading activity was slightly higher than in the normal period. However, in the sub-prime crisis, we find a considerable reduction (around 10\%) in the three trading activity variables compared to the prior periods. Analyzing the two most important explanatory variables of the overall time-series, we find an improvement in the average credit rating indicating a flight-to-quality during the subprime crisis, which did not occur during the GM/Ford crisis: the average credit rating is 8.6 for the GM/Ford crisis, 8.3 for the normal period, and 7.9 for the sub-prime crisis. Considering the price dispersion measure, we find that the average price dispersion is higher in both crises (47.2 bp in the GM/Ford crisis and $62.1 \mathrm{bp}$ in the sub-prime crisis) compared to the normal period (40.2 bp).

Table 3 presents the results of the regressions for the three sub-periods in column 3 to 5 for specifications of the multivariate model based on all the significant variables. The results show that, at the aggregate level, liquidity plays a dominant role for yield spreads in times of crisis. In the GM/Ford crisis, the price dispersion measure and the Roll measure are significant. In the sub-prime crisis, only the price dispersion measure is significant. The rating variable is not significant for these periods indicating that rating changes in those periods cannot explain yield spread changes at the aggregate level. The $R^{2}$ of $68.5 \%$ in the GM/Ford crisis and $55.1 \%$ in the sub-prime crisis further signify the heightened importance of liquidity in these stressed time periods. On the other hand, for the normal period, only the rating variable is significant and none of the liquidity measures provides explanatory power. This result indicates that the liquidity impact, or more specifically the premium for liquidity stayed at the same low level. We can answer the question of whether liquidity was at all priced for individual bonds only by our cross-sectional analysis in Section 6.2.

The economic impact of the price dispersion measure increases in times of crisis. During the GM/Ford crisis, a one standard deviation move in price dispersion changes the yield spread by $12.5 \mathrm{bp}$ and in the sub-prime crisis by $13.2 \mathrm{bp}$. As expected, the economic impact of liquidity is highest in the sub-prime crisis. Comparing this result with the result for the overall time-series, the economic significance increased by about 50\% during the financial crises, indicating that a significant part of the sharp increase in yield spreads during the financial crises is due to liquidity.

Overall, we find that liquidity is an important driver of corporate yield spreads. Our framework allows us to quantify these effects for the US corporate bond market as a whole, thus providing important insights regarding the validity of alternative liquidity measures at the aggregate market 
level. In the next three sub-sections, we analyze various aspects of the liquidity impact on yield spreads for important segments of the aggregate market.

\subsubsection{Financial vs. Industrial Bonds}

Financial crises are obviously stress scenarios for firms in the financial industry. Especially during the sub-prime crisis, the financial industry was hit by severe losses in financial instruments often related to credit risk, starting with the (structured) sub-prime market and spreading rapidly to other markets. Therefore, it is an interesting research question whether yield spreads of corporate bonds issued by firms in the financial industry show a different relation to liquidity and credit risk in the different periods of our time-series, compared with their industrial counterparts.

Figure 4a shows the time-series of the yield spreads for financial and industrial bonds. In the normal period, financial firms have lower bond yield spreads compared with industrial firms, whereas in times of crises, these differences are closer to zero, and are even negative sometimes, indicating that the yield spread of financial firms reacts strongly in such periods.

Table 5a presents the time-series averages of the explanatory variables in the three sub-periods for financial and industrial firms. We find for the financial firms that the volume and the number of trades is higher in both crises compared to the normal period. However, in the sub-prime crisis a lower number of financial bonds with on average better ratings is traded. Overall this indicates a flight-to-quality for the financial segment. Such an effect cannot be observed for industrial bonds. Considering the price dispersion measure, we find that in the normal period the price dispersion for financial firms (36.4 bp) is on average lower compared to industrial firms (44.2 bp). Interestingly, in the sub-prime crises the difference increases. This may indicate that the spread increase for financial firms was induced relatively more by higher credit risk compared to industrial firms (see Section 6.2 for a detailed discussion.)

Table 6 presents the results of the regressions for the overall time-series and the three subperiods for financial and industrial bonds. We find that the credit rating and the price dispersion measure are the most important explanatory variables. Interestingly, the Amihud measure is significant for bonds of financial firms. This could indicate that the movement in the price due to the high volumes of trading might be more informative for financial bonds. Other liquidity measures show no significant relation to the yield spreads in both groups. Again, we find that the price dispersion measure is more important in times of crisis, while the credit rating is the key determinant of yield spreads in the normal period. Interestingly, the price dispersion parameter is lower (around 50\%) for industrial firms compared with financial firms, although their price dispersion on average is higher. This indicates that the overall liquidity for industrial bonds is

lower. However, financial bonds react more strongly to changes in liquidity. This difference is particularly pronounced during the GM/Ford crisis.

\subsubsection{Investment vs. Speculative Grade}

In this section, we analyze the time-series of bond yield spreads grouped by rating classes. We divide the bonds into investment (AAA to BBB-) and speculative grade (BB+ to $\mathrm{C} / \mathrm{CCC}$ ), expecting liquidity effects of speculative grade bonds to be more pronounced. 
Figure $4 \mathrm{~b}$ shows the yield spreads for the whole time-series. As expected, the investment grade bond yield spread is lower than the one for speculative bonds. However, we stress three important points here: First, the GM/Ford crisis is mainly reflected in the speculative grade spreads, as the GM/Ford bonds were downgraded to junk status and probably had spillover effects in the whole corporate bond market; second, in the normal period, the difference between investment and speculative grade spreads is systematically reduced over time, reflecting the decreasing risk premiums, which received widespread attention in the popular press; third, in the sub-prime crisis, basically both spread series increase dramatically by a factor of three.

Table $5 \mathrm{~b}$ presents the time-series averages of the explanatory variables. We find that, in general, trading is focused on the investment grade segment. In the GM/Ford crisis, we find higher trading activity compared with the normal period especially in the speculative grade segment, perhaps due to the trade volume caused by a shuffling of bonds due to clientele preferencesas a consequence of the downgrades. In the sub-prime crisis, we find lower trading activity for both segments. However, only the investment grade segment shows a flight-to-quality indicated by trading in better rated bonds compared to the normal period. Considering the price dispersion measure, we find that in the normal period the price dispersion for speculative grade bonds (49.0 bp) is higher on average than for investement grade bonds (36.9 bp). Interestingly, the price dispersion of the investment grade bonds reacts more strongly in the sub-prime crisis and, thus, the difference of investment grade relative to the speculative grade bonds was reduced (68.1 vs. $59.4 \mathrm{bp}$ ).

Table 7 presents the results for the time-series regressions for the two rating categories. The significant variables are the rating, the price dispersion, the Roll and the Amihud measure. Most striking is that the price dispersion measure is statistically significant in all three sub-periods for speculative grade bonds, i.e., also in the normal period. This indicates that for speculative bonds, liquidity is an important factor for all three sub-periods. The price dispersion parameter is higher for speculative grade bonds, reflecting the fact that these bonds react more strongly to changes in liquidity. In general, these results show that the liquidity component is far more important for speculative grade bonds, and more so in periods of crisis. The significance of the Amihud measure could indicate that price changes through trading is more apparent for all rated bonds.

\subsubsection{Retail vs. Institutional Trades}

In this section we analyze whether bonds that are mainly traded by retail traders are less liquid than bonds traded by institutional investors. We define two groups based on the average trade size as explained in Section 5 .

Figure 4c shows the yield spread for the two groups. Basically, the average yield spreads are identical with one exception: at the end of 2005 the spread increase is more pronounced for the retail traded bonds, as many GM/Ford bonds were mainly traded by retail investors. In the sub-prime crisis the level of the yield spread is identical for both groups.

Table $5 \mathrm{c}$ presents the time-series averages of the explanatory variables. We find that quite a large number of bonds, around 1,800, falls in the retail trade category and that retail traders invest, on average, in better rated bonds. In the sub-prime crisis, the average rating in the retail group improved, indicating a flight-to-quality by these investors. Even more important is the change 
in the price dispersion measure. In the normal period and in the GM/Ford crisis, we find that for retail trades, the price dispersion is twice as large, indicating much higher transaction costs. Far more striking are the results in the sub-prime crisis, where we find a dramatic increase in the price dispersion for institutional investors (from 24.1 to $52.7 \mathrm{bp}$ ) and only a moderate increase for retail investors (from 49.9 to $64.7 \mathrm{bp}$ ). Thus, liquidity for large trades reduced significantly in the sub-prime crisis.

Table 8 shows the results for the time-series regression for the two categories of trades. The results are similar to those for the overall sample. The estimated coefficient of the price dispersion variable is higher for the institutional group indicating that this group reacts more strongly to changes in the liquidity. The credit rating has explanatory power for all three sub-periods for institutional trades. This may indicate that the rating is more important for institutional traders because they have clear clientele preferences in conformity with their prospectuses. This effect is amplified in times of crisis, when credit rating changes occur with greater frequency. These results indicate that liquidity changes are, in general, more important for institutional trades and that retail traders are generally confronted with higher transaction costs, in line with our expectation.

\subsection{Cross-Sectional Analysis}

In this section, we explore the cross-sectional differences in explaining the bond yield spreads over the Treasury rate by considering the explanatory variables presented in Section 4 . We conduct this analysis for the same three sub-periods as in the time-series analysis, i.e., the GM/Ford crisis, the normal period and the sub-prime crisis. Moreover, we perform the cross-sectional analysis for three different samples: The large sample excluding the bid-ask spread, the medium sample including all variables and the small sample comprising only the actively traded bonds.

Table 9 provides the detailed results where the presented models are based on the significant variables. The explanatory variables can explain a large part of the cross-sectional differences in the yield spread across bonds, represented by a $R^{2}$ ranging between $45.5 \%$ to $77.7 \%$. The $R^{2}$ is highest for the small sample, as it presumably contains more homogenous straight bonds, where the complexities of valuation of bond features such as optionalities and covenants do not arise. However, the general results are very similar for the other samples. The most important variables in all three sub-periods are the credit rating and the price dispersion measure, confirming the timeseries results. For the GM/Ford crisis and the normal period also, the volume is of importance, and for the sub-prime crisis, the Amihud measure, the maturity and the dummy variable for bonds of financial firms are significant. Thus, in contrast to the time-series results, we find that bond characteristics and trading activity are important in explaining cross-sectional differences. ${ }^{17}$

The credit rating has by far the largest explanatory power in the cross-section, with an average marginal $R^{2}$ of $45.3 \%$ in the large sample. For example, a one standard deviation move in the rating variable results in a yield spread change of around 1.8\%. The most important liquidity proxies are the price dispersion measure (marginal $R^{2}$ of $2.0 \%$ ) and the trade volume (marginal $R^{2}$ of $4.3 \%$.) The trade volume indirectly accounts for the cost of trading a certain notional

\footnotetext{
${ }^{17} \mathrm{We}$ also introduced interaction terms between credit and liquidity variables, but they are not statistically significant.
} 
amount of a bond, whereas the price dispersion is a general measure of liquidity that provides information about the cost of being able to trade at all. The price dispersion measure is present as a significant variable in all models, while the trade volume is only significant during the GM/Ford crisis and the normal period. Liquidity effects in the sub-prime crisis can also be explained by the Amihud measure, which is very closely related to the trade volume, but additionally accounts for bond price changes. Regarding the economic effect of the price dispersion measure, a one standard deviation move results in an effect on the yield spread of $24.8 \mathrm{bp}$ in the normal period, $47.2 \mathrm{bp}$ in the GM/Ford crisis and 39.5 bp in the sub-prime crisis based on the large sample. This indicates that the effect of liquidity on the bond yield spread almost doubles during financial crises.

Interestingly, the dummy variable for financial firms is significant for all samples in the subprime crisis. This indicates that, after controlling for the rating, financial firms have, on average, a higher spread. Thus, the yield spread of financial firms reacts more strongly in the crisis than indicated by their rating relative to industrial firms. As this difference seems not to be reflected in the liquidity measures, it appears it is due to the increased credit risk of financial firms, particularly as the ratings are slow to incorporate the impact of changing economic conditions. In general, the credit ratings are a more noisy proxy for credit risk during the sub-prime crisis.

The cross-sectional results also show that the bid-ask spread does not yield any significant contribution towards explaining the cross-sectional differences in the yield spreads. Thus, a reduction of the sample size for including the bid-ask spread cannot be recommended. This is an important result, because the bid-ask spread is often considered as a relevant liquidity proxy both in academia and in the industry. However, based on these results, we conclude that the bid-ask spread is only a very rough proxy for liquidity effects measuring transaction costs.

Overall, the cross-sectional regressions provide additional insights and confirm the important result of the time-series analysis: Liquidity is priced in our samples and liquidity measures related to transaction costs are important in capturing this effect. The overall impact of liquidity is stronger in financial crises compared to periods of more normal market activity. Furthermore, we find that financial firms are particularly affected by the sub-prime crisis; however, the yield spread increase for bonds of financial firms is presumably induced relatively more by higher credit risk compared to industrial firms, during periods of crisis.

\section{Conclusion}

Financial economists have been concerned with the impact of liquidity and liquidity risk on the pricing of assets for at least two decades. During this period, several issues relating to liquidity effects in asset prices have been analyzed at a theoretical and empirical level by academic researchers, particularly in the context of US equity markets. More recently, the focus on liquidity has been broadened to include a wider class of assets such as derivatives and fixed income securities. This trend has accelerated since the onset of the on-going sub-prime crisis, as the discussion of liquidity has attracted much interest among academics, practitioners and regulators. While the crisis has manifested itself in almost every financial market in the world, the most stressed markets, by far, have been those for fixed income securities and their derivatives, particularly those with credit risk, including corporate bonds, CDSs and CDOs. These developments require that the scope of the discussion of liquidity be extended to include the interplay between liquidity and credit. 
Corporate bond markets are far less liquid than related equity markets, since only a very small proportion of the universe of corporate bonds trades even as often as once a day. In addition, corporate bonds trade in an over-the-counter market, where there is no central market place. Hence, conventional transaction metrics of liquidity such as bid-offer quotes do not have the same meaning in this market compared to exchange-traded markets. The issue of liquidity in this relatively illiquid, OTC market is fundamentally different from that in liquid, exchangetraded markets: Thus, it is necessary to use measures of liquidity that go beyond the standard transaction-based measures common in research in more liquid, exchange-traded markets.

We provide both time-series and cross-sectional evidence of the effect of liquidity in the US corporate bond market by employing a wide range of liquidity measures. In our time-series analysis, we find that liquidity effects explain about one-third of the variation in the aggregate yield spread, with this result becoming even more pronounced during periods of crisis. We find, in particular, that the price dispersion measure proposed by Jankowitsch et al. (2008), as a measure of transaction costs, explains approximately half of the market-wide yield spread changes over time during the sub-prime crisis. Surprisingly, neither direct measures of trading activity, such as trade volume, nor other commonly-used liquidity measures, show significant explanatory power. Thus, one important result is that yield spread changes cannot be explained by trading activity alone, but rather by measures of transaction costs in the market, as motivated by the market microstructure literature.

Analyzing the different market segments, we find that the overall liquidity of bonds issued by financial firms is higher on average, than those of industrial firms. Although we show that bonds of financial firms react more strongly to changes in liquidity in general, we find evidence that during the sub-prime crisis the yield spread increase for financial firms compared to industrial firms is driven relatively more by credit risk. Comparing investment grade to speculative grade bonds, we find lower liquidity for speculative bonds as well as a stronger reaction to changes in liquidity, indicating that the liquidity component is far more important in explaining the yield spread for speculative grade bonds. Analyzing retail trades vs. institutional trades, we show that retail investors are confronted with far higher transaction costs, i.e., they perceive the corporate bond market to be relatively less liquid. However, institutional investors seem to react more strongly to liquidity changes than their retail counterparts.

Our cross-sectional results paint a picture similar to the time-series analysis, i.e., liquidity is an important driver of bond-specific differences in yield spreads, with the price dispersion measure showing the sharpest effects. Overall, our time-series and cross-section results provide important insights concerning the effects of liquidity in the US corporate bond market. These results are useful for many practical applications, particularly pricing and risk management, and also have implications for regulatory policy. They also highlight the importance of transparency of trades for OTC markets, with reporting to a central authority being a crucial element for price discovery.

Several interesting questions for future research arise from our findings in this study: What is the linkage between liquidity in the corporate bond market compared to the market for the underlying equity? What is the linkage between the corporate bond market and the CDS market? How do these linkages change during periods of crisis compared to normal times? We defer these issues to future research. 


\section{A Tables and Figures}

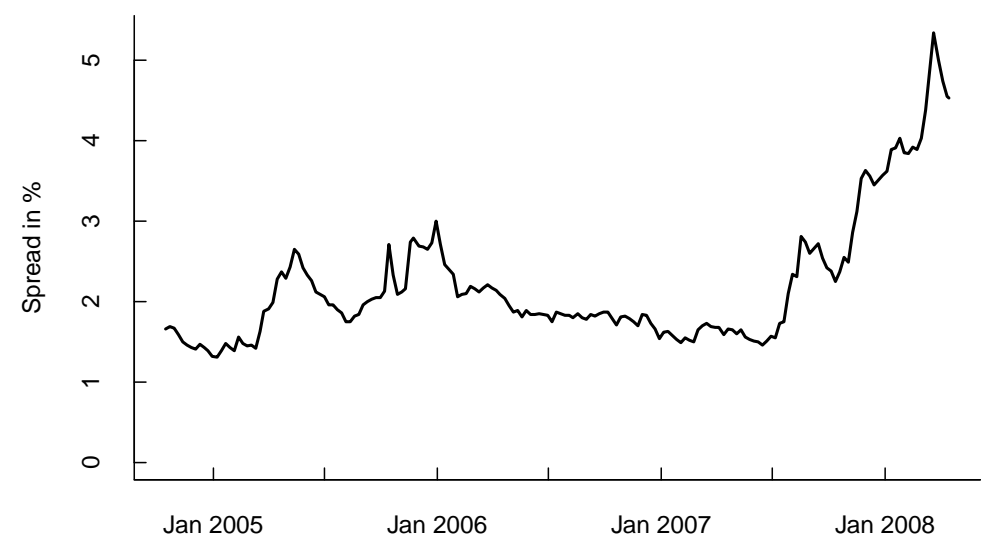

Figure 1: This figure shows the market-wide corporate bond yield spread between October 2004 and April 2008 computed by averaging the bond yield spreads across bonds traded. Corporate bond yield spreads are measured relative to the Treasury yield curve and are given in percentage points. The data-set consists of 31,911 bonds traded over the period October 2004 to April 2008 and is derived from four main sources: TRACE, Markit, Bloomberg and Standard and Poor's.

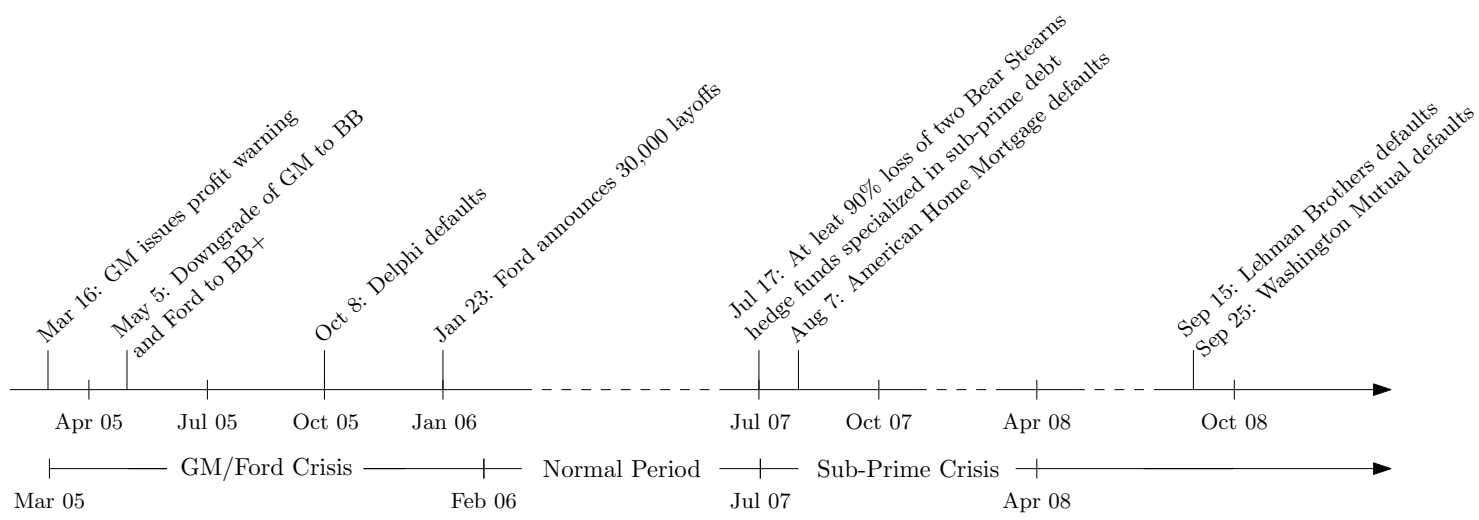

Figure 2: Time-line exhibiting important events since March 2005. Based on these events we identified three different regimes: the GM/Ford crisis between March 2005 and January 2006, the normal period from February 2006 to June 2007, with no exceptional events and the sub-prime crisis that started in July 2007. 


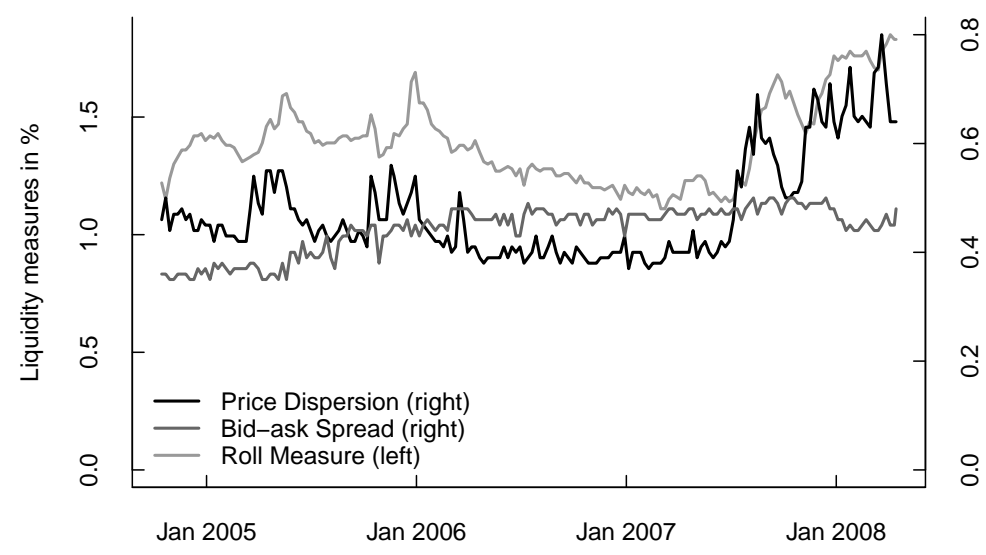

Figure 3: This figure exhibits the time-series behavior of three proxies of transaction costs. We plot the market-wide price dispersion measure against the Roll measure and the bid-ask spread in the time-period of October 2004 to April 2008. The price dispersion measure is an estimate of transaction costs based on the variance of prices around the consensus market valuation. The Roll measure is an estimate of the bid-ask spread based on the serial covariance of price changes. The Roll measure is given on the left axis in percentage points, the price dispersion and the bid-ask spread are given on the right axis, also in percentage points. The data-set consists of 31,911 bonds traded over the period October 2004 to April 2008 and is derived from four main sources: TRACE, Markit, Bloomberg and Standard and Poor's. 
(a) Financial vs. Industrial

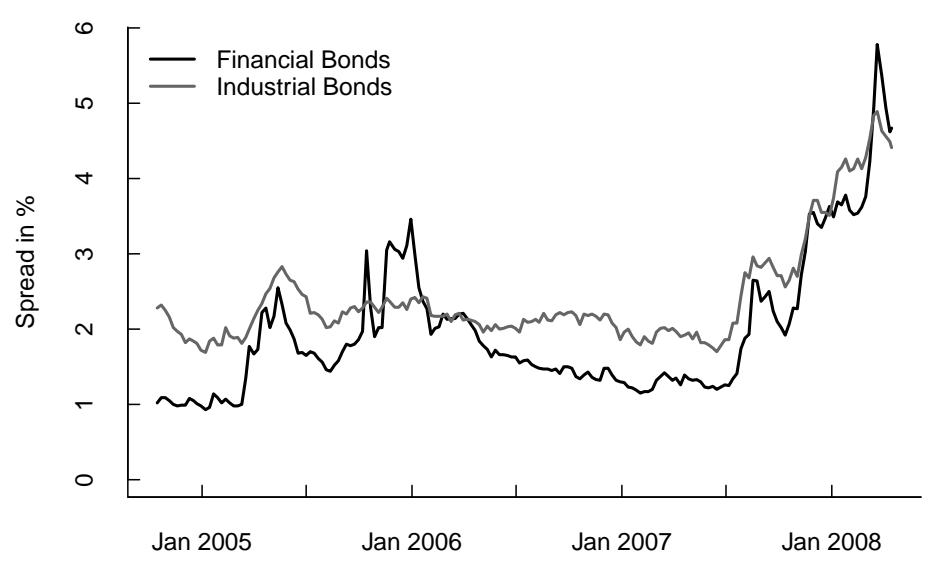

(b) Investment vs. Speculative

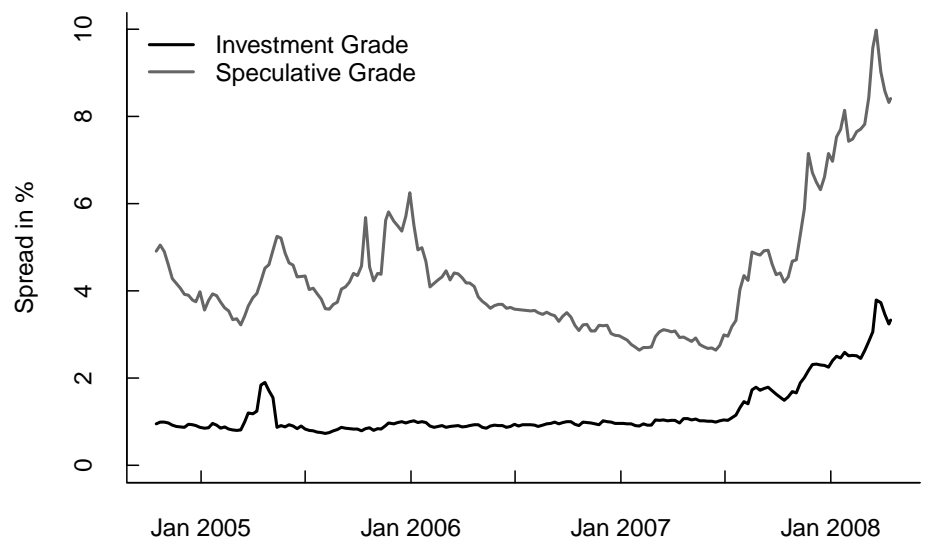

(c) Retail vs. Institutional

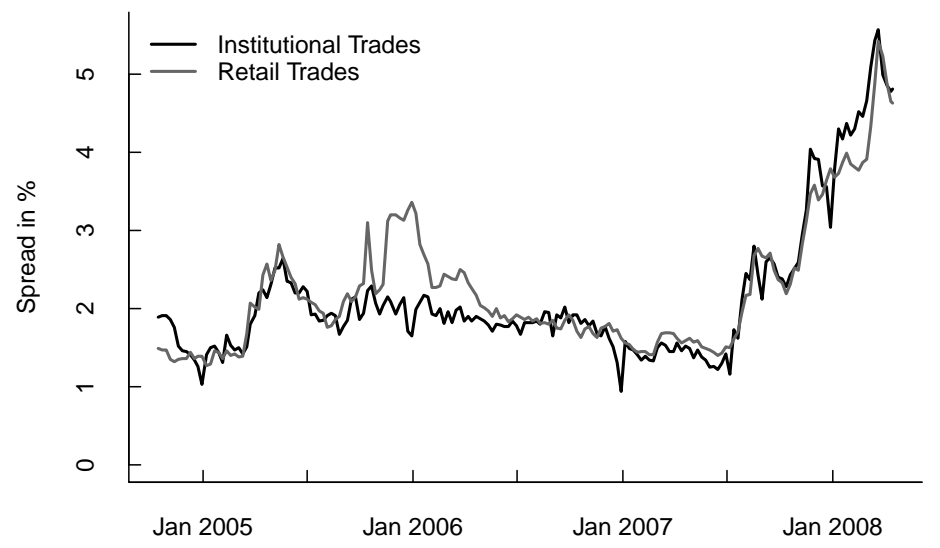

Figure 4: Market-wide bond yield spreads of financial vs. industrial bonds (a), investment grade vs. speculative grade bonds (b), and retail vs. institutional traded bonds (c). We define retail trades as trades with an average trade volume of less than $\$ 25,000$ and institutional trades as trades of more than $\$ 500,000$. The data-set consists of 31,911 bonds traded over the period October 2004 to April 2008 and is derived from four main sources: TRACE, Markit, Bloomberg and Standard and Poor's. 


\begin{tabular}{lccrrrrr}
\hline & $Q_{0.05}$ & $Q_{0.25}$ & \multicolumn{1}{c}{$Q_{0.50}$} & \multicolumn{1}{c}{$Q_{0.75}$} & \multicolumn{1}{c}{$Q_{0.95}$} & \multicolumn{1}{c}{ Mean } & Std. Dev. \\
\hline Yield Spread (\%) & 0.044 & 0.985 & 1.390 & 2.370 & 5.869 & 2.146 & 3.188 \\
Rating & 1.000 & 4.000 & 6.000 & 9.000 & 15.000 & 6.989 & 4.113 \\
Amount Issued (mln) & 0.674 & 3.643 & 46.374 & 250.000 & 1000.000 & 219.503 & 415.841 \\
Coupon (\%) & 2.500 & 4.600 & 5.630 & 6.900 & 9.380 & 5.713 & 2.118 \\
Maturiy (yr) & 0.508 & 1.649 & 4.522 & 9.466 & 23.949 & 7.288 & 7.686 \\
Age (yr) & 0.507 & 1.338 & 2.326 & 4.351 & 11.028 & 3.665 & 3.722 \\
Trades per day & 1.596 & 2.150 & 2.609 & 3.500 & 8.877 & 4.389 & 33.538 \\
Volume (mln) & 0.029 & 0.056 & 0.183 & 1.953 & 7.207 & 2.278 & 42.226 \\
Price Dispersion (\%) & 0.001 & 0.121 & 0.247 & 0.438 & 0.869 & 0.324 & 0.473 \\
Bid-Ask Spread (\%) & 0.121 & 0.250 & 0.378 & 0.543 & 0.835 & 0.416 & 0.209 \\
Amihud (10-8) & 0.002 & 0.110 & 0.455 & 1.083 & 2.529 & 0.810 & 1.541 \\
Roll (\%) & 0.762 & 1.213 & 1.384 & 1.570 & 2.117 & 1.416 & 0.468 \\
Zero-Ret. (Markit) (\%) & 0.000 & 0.000 & 0.375 & 2.186 & 14.000 & 2.660 & 6.217 \\
Zero-Ret. (Bloomb.) (\%) & 0.000 & 0.000 & 0.000 & 0.746 & 13.901 & 2.240 & 6.663 \\
No-Trade (\%) & 28.509 & 59.124 & 91.082 & 97.654 & 99.488 & 77.444 & 25.797 \\
\hline
\end{tabular}

Table 1: This table reports the cross-sectional descriptive statistics for the yield spread, the credit rating, bond characteristics, trading activity variables, and liquidity measures. For time-varying variables, the statistics are based on averages for each individual bond. The data-set consists of 31,911 bonds traded over the period October 2004 to April 2008 and is derived from four main sources: TRACE, Markit, Bloomberg and Standard and Poor's. 


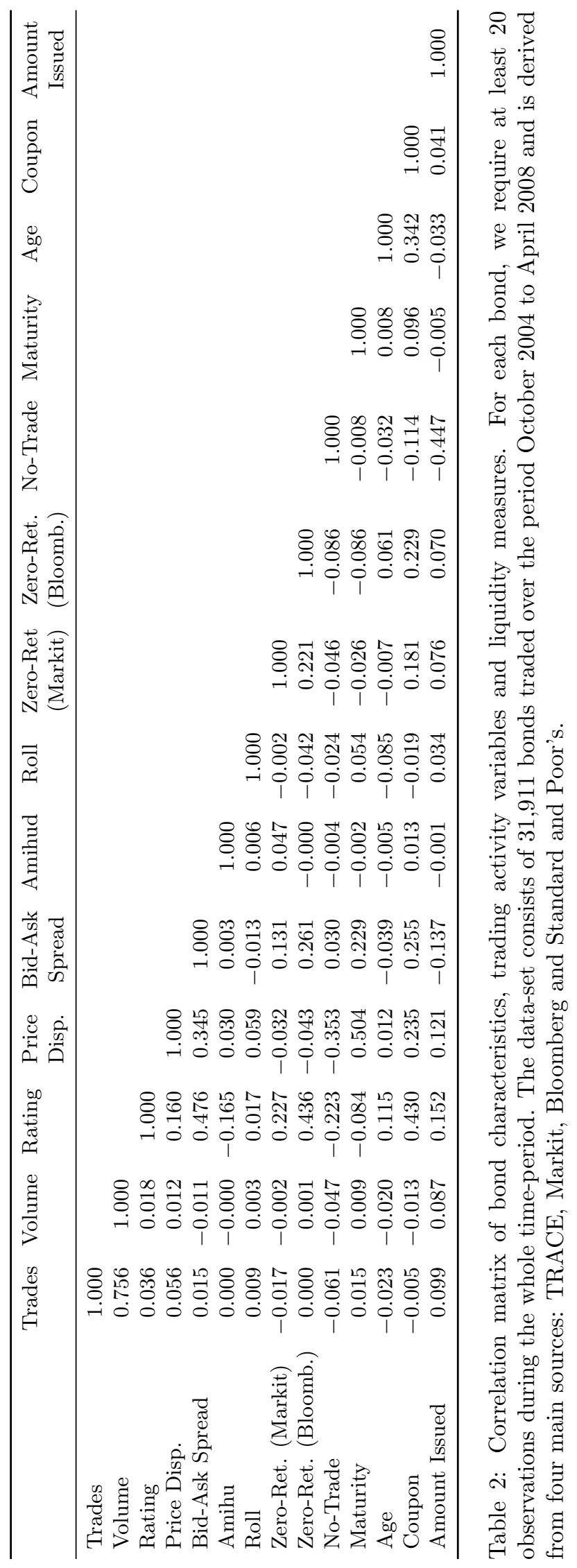




\begin{tabular}{|c|c|c|c|c|c|}
\hline & $\begin{array}{c}\text { Total } \\
\text { Period I }\end{array}$ & $\begin{array}{c}\text { Total } \\
\text { Period II }\end{array}$ & $\begin{array}{l}\text { GM/Ford } \\
\text { Crisis }\end{array}$ & $\begin{array}{l}\text { Normal } \\
\text { Period }\end{array}$ & $\begin{array}{l}\text { Sub-prime } \\
\text { Period }\end{array}$ \\
\hline Intercept & $\begin{array}{c}0.0118 \\
(1.1965)\end{array}$ & $\begin{array}{c}0.0117 \\
(1.2580)\end{array}$ & $\begin{array}{c}0.0157 \\
(1.0831)\end{array}$ & $\begin{array}{c}-0.0074 \\
(-1.0482)\end{array}$ & $\begin{array}{c}0.0563^{*} \\
(1.7735)\end{array}$ \\
\hline Lagged $\Delta$ Yld.Spr. & $\begin{array}{c}0.1665^{* *} \\
(2.1698)\end{array}$ & $\begin{array}{r}0.1425^{*} \\
(1.8706)\end{array}$ & $\begin{array}{c}-0.0102 \\
(-0.0668)\end{array}$ & $\begin{array}{c}0.0676 \\
(0.5737)\end{array}$ & $\begin{array}{l}0.3257^{* *} \\
(2.1397)\end{array}$ \\
\hline$\Delta$ Rating & $\begin{array}{l}0.2668^{* * *} \\
(3.2171)\end{array}$ & $\begin{array}{l}0.1727^{* * *} \\
(3.0682)\end{array}$ & & $\begin{array}{l}0.2466^{* * *} \\
(5.3024)\end{array}$ & \\
\hline$\Delta$ Price Dispersion & $\begin{array}{l}2.1478^{* * *} \\
(8.8143)\end{array}$ & $\begin{array}{c}2.4079^{* * *} \\
(10.7616)\end{array}$ & $\begin{array}{l}3.3726^{* * * *} \\
(7.3104)\end{array}$ & & $\begin{array}{l}2.5271^{* * *} \\
(6.6885)\end{array}$ \\
\hline$\Delta$ Bid-Ask Spread & $\begin{array}{c}0.4279 \\
(0.7366)\end{array}$ & & & & \\
\hline$\Delta$ Amihud Measure & $\begin{array}{c}0.0936 \\
(0.7171)\end{array}$ & & & & \\
\hline$\Delta$ Roll Measure & $\begin{array}{l}0.5899^{* * *} \\
(2.6506)\end{array}$ & $\begin{array}{l}0.5609^{* * *} \\
(2.7101)\end{array}$ & $\begin{array}{l}0.8468^{* *} \\
(2.5322)\end{array}$ & & \\
\hline$\Delta$ Zero-Return Measure & $\begin{array}{c}0.3326 \\
(0.4725)\end{array}$ & & & & \\
\hline$\Delta$ No-Trade Measure & $\begin{array}{c}1.1838 \\
(0.3118)\end{array}$ & & & & \\
\hline$\Delta$ Traded Bonds & $\begin{array}{c}-0.0797 \\
(-0.2669)\end{array}$ & & & & \\
\hline$\Delta$ Trades & $\begin{array}{c}0.0156^{*} \\
(1.7641)\end{array}$ & & & & \\
\hline$\Delta$ Volume & $\begin{array}{c}0.0076 \\
(0.7624)\end{array}$ & & & & \\
\hline$R^{2}$ & 0.4756 & 0.4629 & 0.6852 & 0.2581 & 0.5508 \\
\hline Observations & 184 & 184 & 48 & 74 & 42 \\
\hline
\end{tabular}

Table 3: This table reports the time-series regression models explaining the yield spread changes based on weekly data and estimated for the total period, the GM/Ford crisis, the normal period and the sub-prime period. The first column provides a model where the credit rating, all trading activity variables, and liquidity measures are included. The other columns report multivariate regressions based on the significant factors after a step-wise model building. The $t$-statistics are given in parenthesis. In addition, the table also reports each model's $R^{2}$ and the number of observations. The data-set consists of 31,911 bonds traded over the period October 2004 to April 2008 and is derived from four main sources: TRACE, Markit, Bloomberg and Standard and Poor's. 

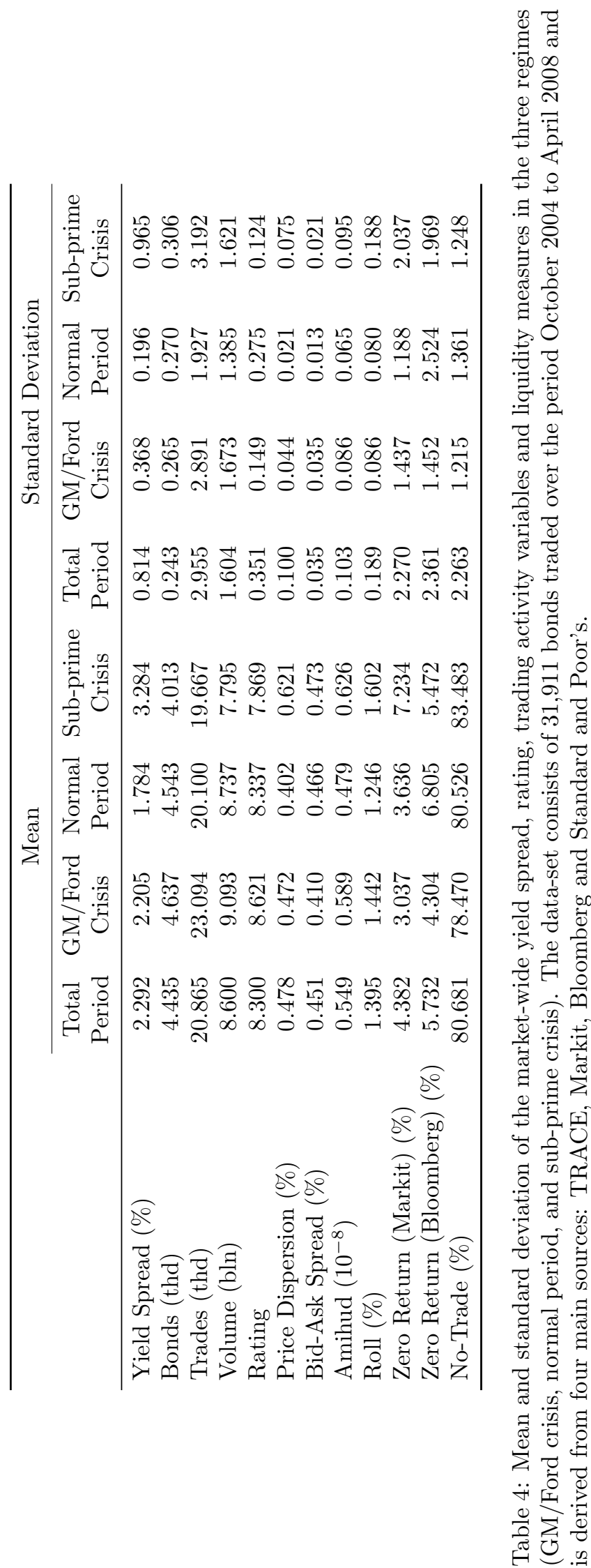
(a) Financial vs. Industrial

\begin{tabular}{lcccccc}
\hline & \multicolumn{2}{c}{ GM/Ford Crisis } & \multicolumn{2}{c}{ Normal Period } & \multicolumn{2}{c}{ Sub-prime Crisis } \\
\cline { 2 - 7 } & Financial & Industrial & Financial & Industrial & Financial & Industrial \\
\hline Yield Spread (\%) & 2.063 & 2.313 & 1.522 & 2.036 & 3.090 & 3.431 \\
Bonds (thd) & 2.364 & 2.276 & 2.305 & 2.242 & 2.044 & 1.981 \\
Trades (thd) & 11.421 & 11.696 & 9.512 & 10.598 & 10.658 & 9.106 \\
Volume (bln) & 3.841 & 5.660 & 3.212 & 5.549 & 3.229 & 4.681 \\
Rating & 7.138 & 10.136 & 6.596 & 10.203 & 5.825 & 10.029 \\
Price Dispersion (\%) & 0.450 & 0.495 & 0.364 & 0.442 & 0.554 & 0.693 \\
\hline
\end{tabular}

(b) Investment vs. Speculative

\begin{tabular}{lrrrrrr}
\hline & \multicolumn{2}{c}{ GM/Ford Crisis } & \multicolumn{2}{c}{ Normal Period } & \multicolumn{2}{c}{ Sub-prime Crisis } \\
\cline { 2 - 7 } & \multicolumn{1}{c}{ IG } & \multicolumn{1}{c}{ SG } & \multicolumn{1}{c}{ IG } & \multicolumn{1}{c}{ SG } & \multicolumn{1}{c}{ IG } & \multicolumn{1}{c}{ SG } \\
\hline Yield Spread (\%) & 0.969 & 4.495 & 0.955 & 3.349 & 2.154 & 6.163 \\
Bonds (thd) & 2.505 & 1.354 & 2.520 & 1.248 & 2.225 & 0.915 \\
Trades (thd) & 11.951 & 7.846 & 11.077 & 5.733 & 10.790 & 4.105 \\
Volume (bln) & 5.315 & 2.221 & 5.167 & 1.592 & 3.796 & 1.222 \\
Rating & 6.049 & 13.435 & 5.642 & 13.659 & 5.442 & 13.720 \\
Price Dispersion (\%) & 0.412 & 0.619 & 0.369 & 0.490 & 0.594 & 0.681 \\
\hline
\end{tabular}

(c) Retail vs. Institutional

\begin{tabular}{lcccccc}
\hline & \multicolumn{2}{c}{ GM/Ford Crisis } & \multicolumn{2}{c}{ Normal Period } & \multicolumn{2}{c}{ Sub-prime Crisis } \\
\cline { 2 - 7 } & Retail & Inst. & Retail & Inst. & Retail & Inst. \\
\hline Yield Spread (\%) & 2.369 & 2.044 & 1.795 & 1.661 & 3.294 & 3.463 \\
Bonds (thd) & 1.866 & 1.110 & 1.809 & 1.102 & 1.617 & 0.972 \\
Trades (thd) & 5.663 & 5.525 & 5.318 & 5.001 & 5.030 & 4.794 \\
Volume (bln) & 0.080 & 7.229 & 0.073 & 7.195 & 0.070 & 6.545 \\
Rating & 7.895 & 10.070 & 7.536 & 9.776 & 7.058 & 9.881 \\
Price Dispersion (\%) & 0.559 & 0.303 & 0.499 & 0.241 & 0.647 & 0.527 \\
\hline
\end{tabular}

Table 5: This table reports the market-wide averages of various explanatory variables in the three different regimes (GM/Ford crisis, normal period, and sub-prime crisis) for bonds of financial vs. industrial firms (a), investment grade vs. speculative grade bonds (b), and retail vs. institutional traded bonds (c). We define retail trades as trades with an average trade volume of less than $\$ 25,000$ and institutional trades as trades of more than $\$ 500,000$. The data-set consists of 31,911 bonds traded over the period October 2004 to April 2008 and is derived from four main sources: TRACE, Markit, Bloomberg and Standard and Poor's. 


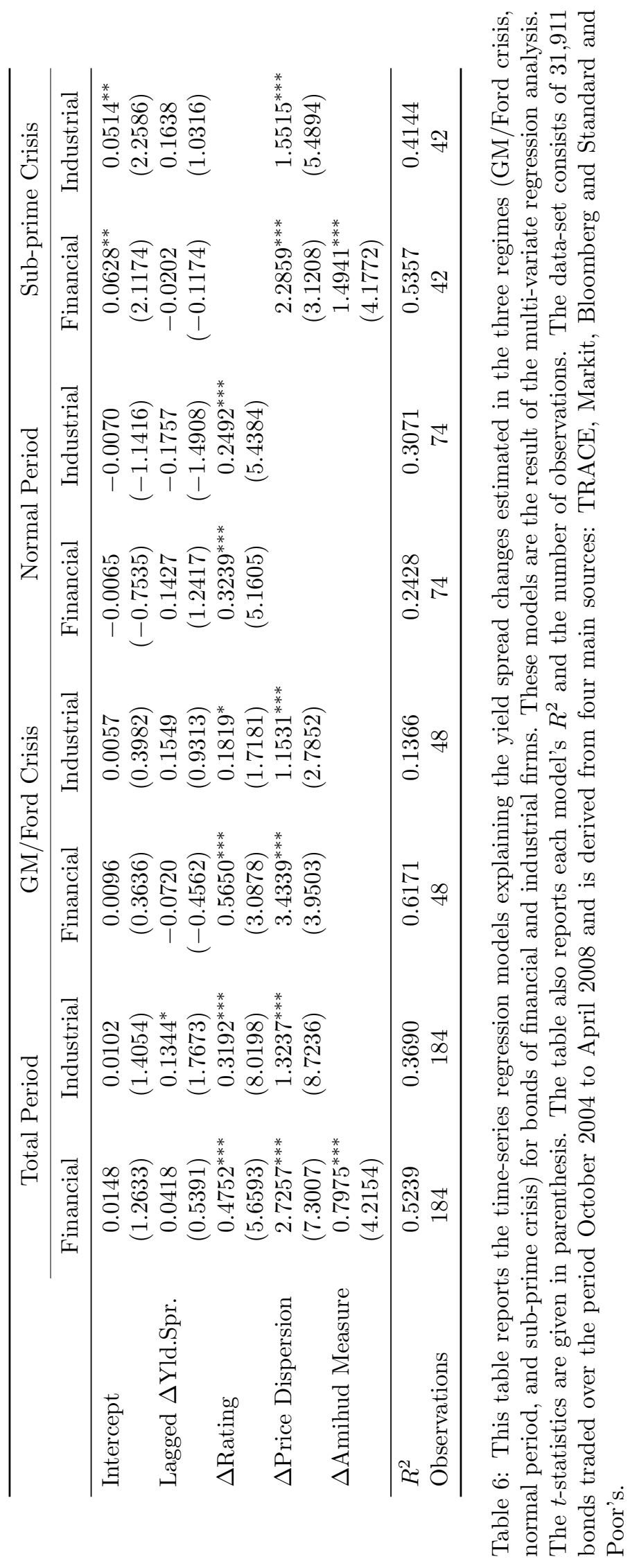




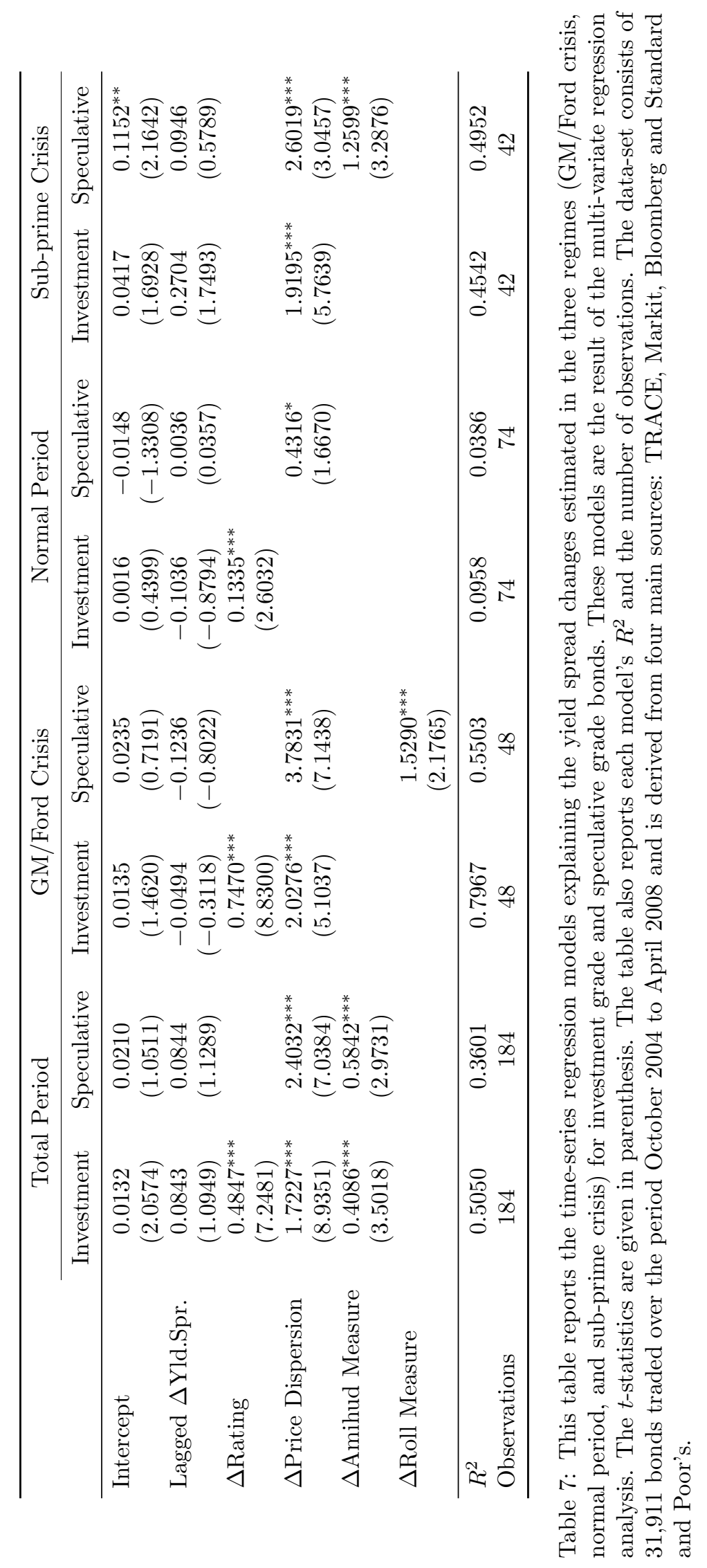




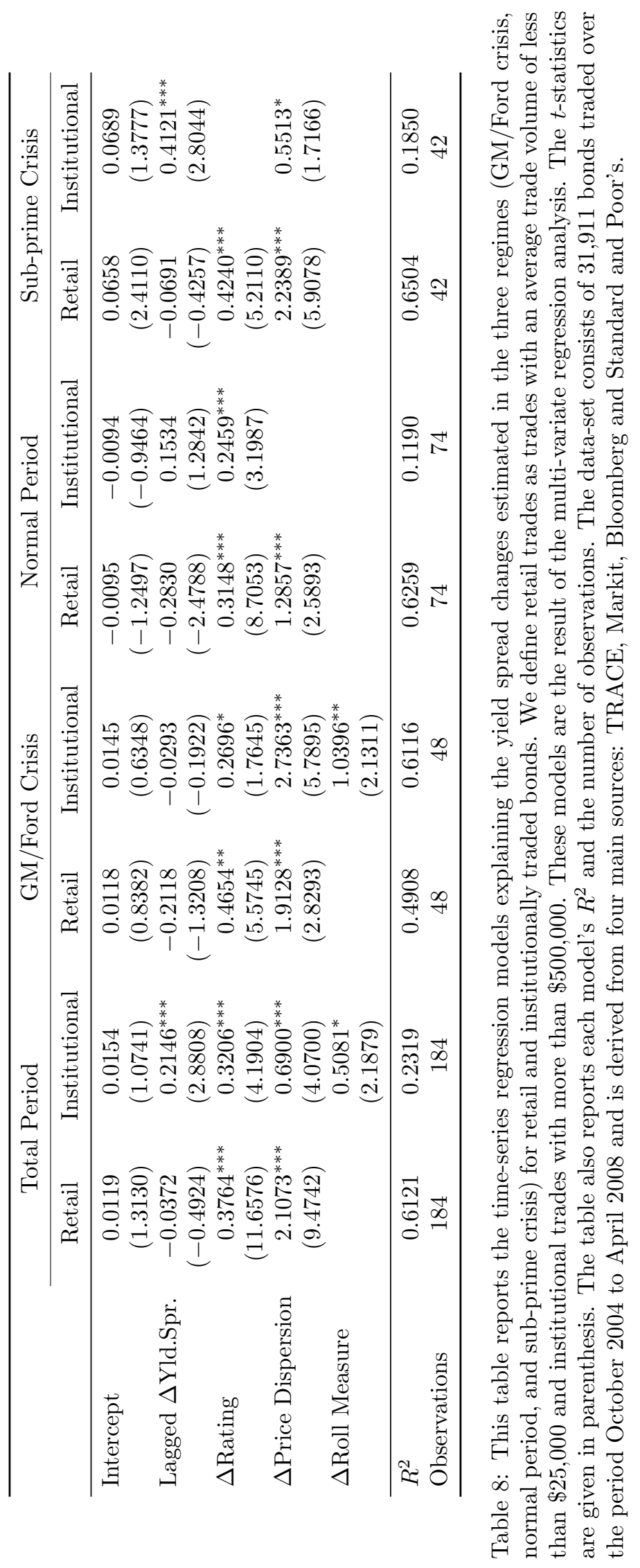




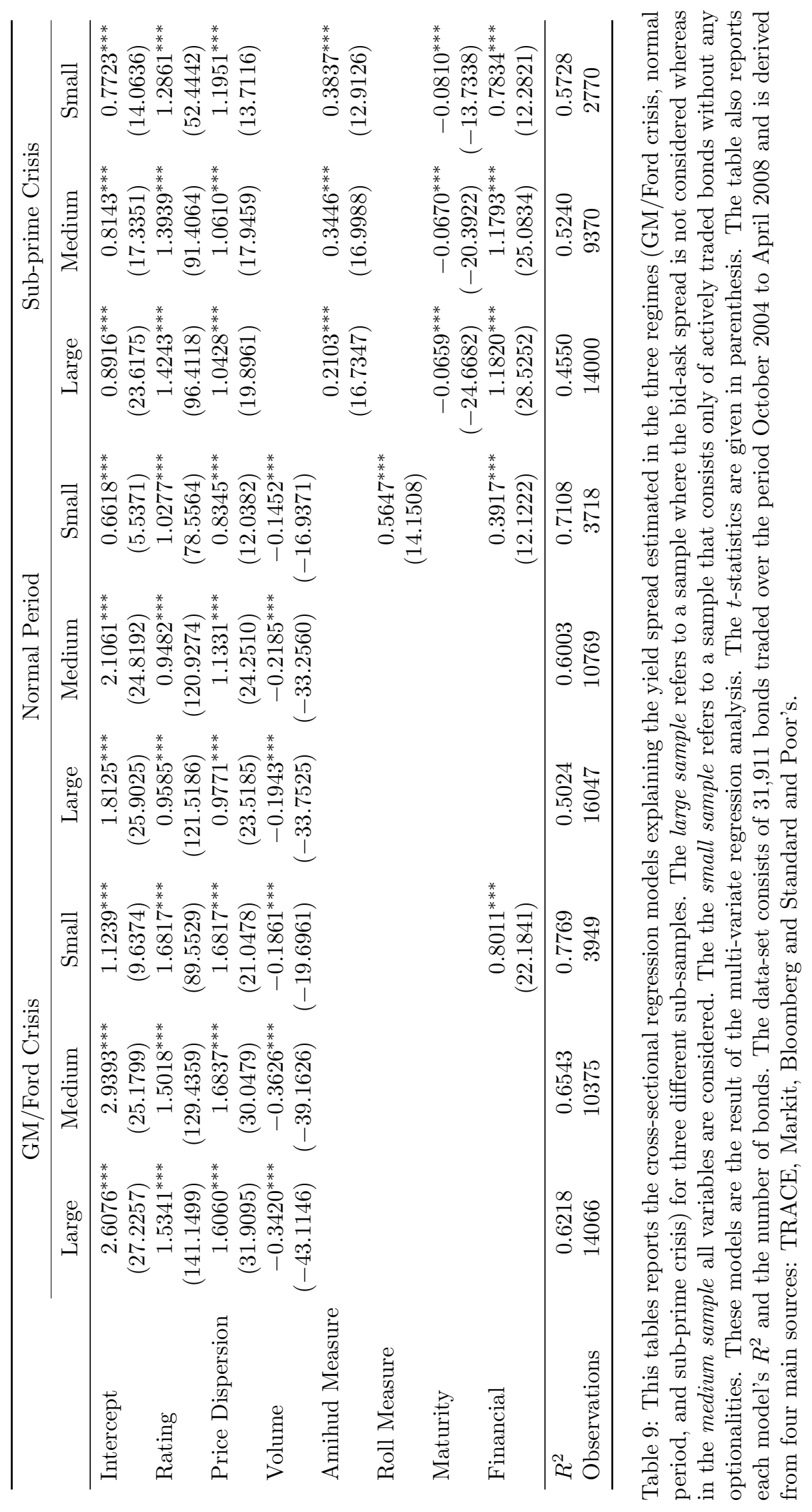




\section{References}

Amihud, Y. (2002). Illiquidity and stock returns: cross-section and time series effects. Journal of Financial Markets 5, 31-56.

Amihud, Y. and H. Mendelson (1986). Asset pricing and the bid-ask spread. Journal of Financial Economics 17, 223-249.

Amihud, Y., H. Mendelson, and L. H. Pedersen (2006). Liquidity and asset prices. Foundations and Trends in Finance 1, 269-364.

Bao, J., J. Pan, and J. Wang (2009). Liquidity and corporate bonds. Working Paper, MIT Sloan School of Management.

Chakravarty, S. and A. Sarkar (1999). Liquidity in u.s. fixed income markets: A comparison of the bid-ask spread in corporate, government and municipal bond markets. Federal Reserve Bank of New York Staff Report No. 73.

Chen, L., D. A. Lesmond, and J. Wei (2007). Corporate yield spreads and bond liquidity. Journal of Finance 62, 119-149.

Collin-Dufresne, P., R. S. Goldstein, and J. S. Martin (2001). The determinants of credit spread changes. Journal of Finance 56, 2177-2207.

De Jong, F. and J. Driessen (2006). Liquidity risk premia in corporate bond markets. Working Paper, University of Amsterdam.

Dick-Nielsen, J., P. Feldhütter, and D. Lando (2009). Corporate bond liquidity before and after the onset of the subprime crisis. Working Paper, Copenhagen Business School.

Duffie, D. and K. J. Singleton (1999). Modeling term structures of defaultable bonds. Review of Financial Studies 12(4), 687-720.

Edwards, A., L. Harris, and M. Piwowar (2007). Corporate bond market transaction costs and transparency. Journal of Finance 62, 1421-1451.

Elton, E. J., M. Gruber, D. Agrawal, and C. Mann (2001). Explaining the rate spread on corporate bonds. Journal of Finance 56, 247-277.

Eom, Y., H. J. Helwege, and J. Z. Huang (2004). Structural models of corporate bond pricing: An empirical investigation. Review of Financial Studies 17, 499-544.

Fisher, L. (1959). Determinants of the risk premiums on corporate bonds. Journal of Political Economy 67, 217-237.

Goldstein, M. A. and E. S. Hotchkiss (2007). Dealer behavior and the trading of newly issued corporate bonds. Working Paper.

Hong, G. and A. Warga (2000). An empirical study of bond market transactions. Financial Analysts Journal 56, 32-46. 
Hotchkiss, E. S. and T. Ronen (2002). The informational efficiency of the corporate bond market: An intraday analysis. Review of Financial Studies 15, 1325-1354.

Houweling, P., A. Mentink, and T. Vorst (2005). Comparing possible proxies of corporate bond liquidity. Journal of Banking and Finance 29(6), 1331-1358.

Huang, J. and M. Huang (2003). How much of the corporate-treasury yield spread is due to credit risk. Working Paper, Stanford University.

Jankowitsch, R., A. Nashikkar, and M. Subrahmanyam (2008). Price dispersion in otc markets: A new measure of liquidity. Working Paper, New York University and Vienna University of Economics and Business.

Kyle, A. S. (1985). Continuous auctions and insider trading. Econometrica 53, 1315-1335.

Lesmond, D. A., J. Ogden, and C. Trzcinka (1999). A new estimate of transaction costs. Review of Financial Studies 12, 1113-1141.

Liu, J., F. A. Longstaff, and R. E. Mandell (2004). The market price of credit risk: An empirical analysis of interest rate swap spreads. Journal of Business 79, 2337-2359.

Longstaff, F., S. Mithal, and E. Neis (2005). Corporate yield spreads: Default risk or liquidity? new evidence from the credit-default swap market. Journal of Finance 60, 2213-2253.

Mahanti, S., A. Nashikkar, M. Subrahmanyam, G. Chacko, and G. Mallik (2008). Latent liquidity: a new measure of liquidity, with an application to corporate bonds. Journal of Financial Economics 88, 272-298.

Markit (2006). Markit.com user guide - version 8.0 march 2006. User guide, Markit Group Limited.

Nashikkar, A., M. Subrahmanyam, and S. Mahanti (2009). Limited arbitrage and liquidity in the market for credit risk. Working Paper.

Perraudin, W. and A. Taylor (2003). Liquidity and bond market spreads. Working Paper, Bank of England.

Roll, R. (1984). A simple implicit measure of the effective bid-ask spread in an efficient market. Journal of Finance 39, 1127-1139.

Ronen, T. and X. Zhou (2009). Where did all the information go? trade in the corporate bond market. Working Paper, Rutgers University.

Schultz, P. (2001). Corporate bond trading costs and practices: A peek behind the curtain. Journal of Finance 56, 677-698.

Standard \& Poor's (2008). Default, transition, and recovery: 2007 annual global corporate default study and rating transitions. Technical report. 